\title{
Comparison of OMI UV observations with ground-based measurements at high northern latitudes
}

\author{
G. Bernhard ${ }^{1}$, A. Arola ${ }^{2}$, A. Dahlback ${ }^{3}$, V. Fioletov ${ }^{4}$, A. Heikkilä ${ }^{5}$, B. Johnsen ${ }^{6}$, T. Koskela ${ }^{5}$, K. Lakkala ${ }^{7}$, \\ T. Svendby ${ }^{8}$, and J. Tamminen ${ }^{5}$ \\ ${ }^{1}$ Biospherical Instruments Inc., San Diego, California, USA \\ ${ }^{2}$ Finnish Meteorological Institute, Kuopio, Finland \\ ${ }^{3}$ Department of Physics, University of Oslo, Oslo, Norway \\ ${ }^{4}$ Environment Canada, Toronto, Ontario, Canada \\ ${ }^{5}$ Finnish Meteorological Institute, Helsinki, Finland \\ ${ }^{6}$ Norwegian Radiation Protection Authority, Østerås, Norway \\ ${ }^{7}$ Finnish Meteorological Institute, Arctic Research Centre, Sodankylä, Finland \\ ${ }^{8}$ Norwegian Institute for Air Research, Kjeller, Norway
}

Correspondence to: G. Bernhard (bernhard@biospherical.com)

Received: 04 February 2015 - Published in Atmos. Chem. Phys. Discuss.: 25 March 2015

Revised: 06 June 2015 - Accepted: 17 June 2015 - Published: 09 July 2015

\begin{abstract}
The Dutch-Finnish Ozone Monitoring Instrument (OMI) on board NASA's Aura spacecraft provides estimates of erythemal (sunburning) ultraviolet (UV) dose rates and erythemal daily doses. These data were compared with ground-based measurements at 13 stations located throughout the Arctic and Scandinavia from 60 to $83^{\circ} \mathrm{N}$. The study corroborates results from earlier work, but is based on a longer time series ( 8 versus 2 years) and considers additional data products, such as the erythemal dose rate at the time of the satellite overpass. Furthermore, systematic errors in satellite UV data resulting from inaccuracies in the surface albedo climatology used in the OMI UV algorithm are systematically assessed. At times when the surface albedo is correctly known, OMI data typically exceed ground-based measurements by $0-11 \%$. When the OMI albedo climatology exceeds the actual albedo, OMI data may be biased high by as much as $55 \%$. In turn, when the OMI albedo climatology is too low, OMI data can be biased low by up to $59 \%$. Such large negative biases may occur when reflections from snow and ice, which increase downwelling UV irradiance, are misinterpreted as reflections from clouds, which decrease the UV flux at the surface. Results suggest that a better OMI albedo climatology would greatly improve the accuracy of OMI UV data products even if year-to-year differences of the actual albedo cannot be accounted for. A pathway for im-
\end{abstract}

proving the OMI albedo climatology is discussed. Results also demonstrate that ground-based measurements from the center of Greenland, where high, homogenous surface albedo is observed year round, are ideally suited to detect systematic problems or temporal drifts in estimates of surface UV irradiance from space.

\section{Introduction}

The Dutch-Finnish Ozone Monitoring Instrument (OMI) on board the NASA EOS Aura spacecraft is a nadir viewing spectrometer that measures solar reflected and backscattered radiation in a selected range of the ultraviolet and visible spectrum. The Finnish Meteorological Institute in collaboration with the NASA Goddard Space Flight Center have developed a surface ultraviolet irradiance algorithm for OMI that produces noontime surface spectral UV irradiance estimates at four wavelengths, noontime erythemal dose rate or the UV index (UVI), and the erythemal daily dose. Tanskanen et al. (2007) (hereinafter referred to as T07) have compared erythemal daily doses derived from OMI observations with doses calculated from ground-based measurements of 18 reference instruments ranging in latitude from $72.6^{\circ} \mathrm{N}$ to $77.8^{\circ} \mathrm{S}$. The present paper presents a similar comparison 


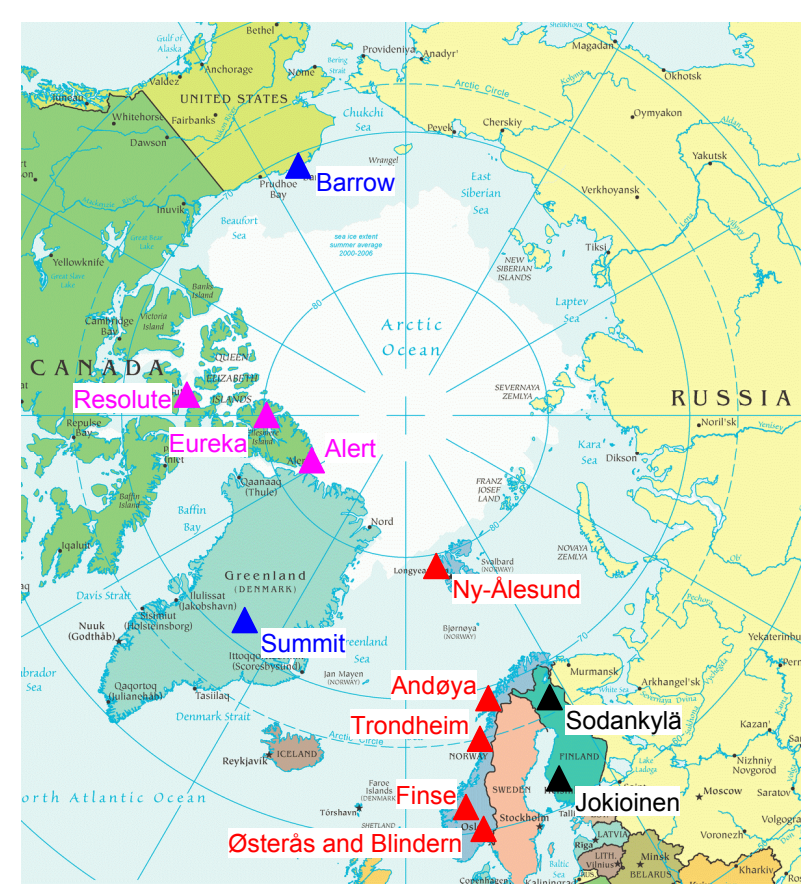

Figure 1. Locations of instruments operated by Environment Canada (pink), Biospherical Instruments (blue), the Norwegian Radiation Protection Authority and the Norwegian Institute of Air Research (red), and the Finnish Meteorological Institute (black).

with focus on Arctic locations. Ground stations include 13 instruments located in Alaska, Canada, Greenland, Norway, Svalbard, and Finland (Fig. 1). These data sets are identical to those used by Bernhard et al. (2013), hereinafter referred to as B13.

Surface albedo from snow and ice covering the ground can enhance the clear-sky UVI by up to $58 \%$ (Fig. 2). The effect is caused by photons that are reflected upward, and subsequently Rayleigh-scattered downward by the overlying atmosphere toward the surface (Lenoble, 1998). Fresh snow can have an albedo as high as 0.98 (Grenfell et al., 1994). Albedo decreases with snow depth but even a thin layer of fresh snow has a higher albedo than any other natural surface. According to Feister and Grewe (1995), the albedo of fresh snow at $310 \mathrm{~nm}$ is 0.62 for a snow depth of $2 \mathrm{~cm}$ and 0.76 for a depth of $5 \mathrm{~cm}$. Calculations of the UVI from spacebased measurements therefore require accurate knowledge of the surface albedo. Because OMI cannot distinguish between snow and clouds, an albedo climatology (Tanskanen, 2004) is used by the OMI UV algorithm. This climatology has unrealistic values at some locations and also does not take changes in albedo from year to year into account. According to T07, systematic errors in OMI UV data can be large (up 50\%) for polar regions because the OMI UV algorithm sometimes uses unrealistically small surface albedo that leads to misinterpretation of the observed bright scene as clouds. An important goal of the present paper is to quantify these systematic errors

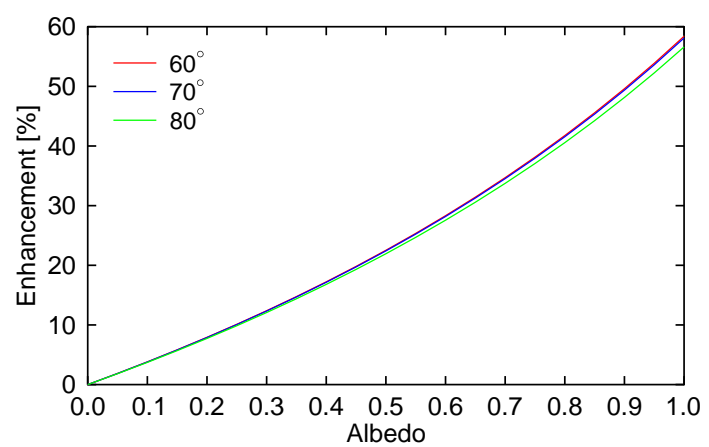

Figure 2. Enhancement of the clear-sky UVI as a function of albedo. The plot is based on radiative transfer calculations with the libRadtran model (Mayer and Kylling, 2005) for sea level, a TOC of $400 \mathrm{DU}$, and SZAs of 60,70 and $80^{\circ}$ as indicated in the legend.

and their causes in greater detail, and to provide recommendations on how these errors could be reduced.

T07 only considered daily erythemal doses. OMI data files also provide the UVI at the time of the satellite overpass and at local solar noon, and these data are also evaluated in the present paper. For estimating the daily dose, the OMI UV algorithm assumes that total ozone column (TOC) and cloud optical depth (COD) remain constant throughout the day, which is unrealistic in most cases. It may therefore be expected that differences between OMI and ground-based measurements assessed for the time of the satellite overpass are smaller than for the daily dose data set. It is a secondary objective of the present paper to determine whether this is indeed the case.

The study by T07 is based on OMI data of the period September 2004-March 2006. The present study considers data measured between September 2004 and December 2012 .

\section{Data sets}

The present paper focuses on the validation of the UVI and the daily erythemal dose. The UVI is a dimensionless number and calculated by weighting the spectral UV irradiance from Sun and sky that is received on a horizontal surface, $E_{\lambda}(\lambda)$, with the action spectrum for erythema, $s_{\mathrm{er}}(\lambda)$, integrating the weighted spectrum over the wavelength range $250-400 \mathrm{~nm}$, and multiplying the result by the constant $k_{\mathrm{er}}$, which is equal to $40 \mathrm{~m}^{2} \mathrm{~W}^{-1}$ (WHO, 2002):

$$
\mathrm{UVI}=k_{\mathrm{er}} \times \int_{250 \mathrm{~nm}}^{400 \mathrm{~nm}} E_{\lambda}(\lambda) s_{\mathrm{er}}(\lambda) d \lambda=k_{\mathrm{er}} \times E_{\mathrm{er}},
$$

where $E_{\text {er }}$ is called the "erythemally weighted irradiance". Both ground-based and OMI data are based on the action spectrum for erythema defined by the Commission Internationale de l'Éclairage (CIE) in 1987 (McKinlay and Dif- 
fey, 1987). The spectrum has been slightly modified in 1998 (CIE, 1998; ISO, 1999). For solar zenith angles (SZAs) smaller than $60^{\circ}$, UVI values calculated with the new norm are approximately $0.5-1.0 \%$ larger than corresponding values calculated with the original standard (Webb et al., 2011). Differences for SZAs between 60 and $90^{\circ}$ are between 1 and $2 \%$.

\subsection{Ground-based data}

Ground-based data are identical with those used by B13 and are from thirteen Arctic and Scandinavian locations (Fig. 1). Sorted by decreasing latitude, the thirteen sites are Alert, Eureka, $N y$-Ålesund, Resolute, Barrow, Summit, Andøya, Sodankylä, Trondheim, Finse, Jokioinen, Østerås, and Blindern. Sites that are italicized use multi-channel filter radiometers, while the other sites use scanning spectroradiometers. Essential information such as the sites' latitude and longitude is provided in Table 1 of B13. Climatic conditions at the 13 sites are summarized by B13 and discussed in more detail in Sect. 5.1. Detailed information on instrumentation, data processing, and measurement uncertainties are also provided by B13. For all instruments but those installed at Sodankylä and Jokioinen, the expanded uncertainty (coverage factor $k=2$ ) of UVI data ranges between 5.8 and $6.2 \%$. For the two Brewer spectrophotometers installed at Sodankylä and Jokioinen, a rigorous uncertainty budget has not been developed. However, the two instruments have participated in several intercomparision campaigns and were also regularly compared with the QASUME (Quality Assurance of Spectral UV Measurements in Europe) reference spectroradiometer (Bais et al., 2003). Measurements were consistently high by 1-6\% compared to measurements of the QASUME instrument. Data have not been adjusted to the irradiance scale of the QASUME instrument because the difference of 1-6\% is within the uncertainty of UV measurements of the QASUME instrument (Gröbner et al., 2005) and that from other ground stations.

The erythemal daily dose was calculated by integrating measurements over $24 \mathrm{~h}$ periods centered at local solar noon. Methods to fill data gaps have been described by B13.

\subsection{OMI data}

Details of the OMI surface UV algorithm have been discussed in detail by T07 and references therein. In brief, the algorithm first estimates the clear-sky surface irradiance using the OMI-measured total column ozone, climatological surface albedo (Tanskanen, 2004), elevation, solar zenith angle (SZA), and latitude-dependent climatological ozone and temperature profiles. Next, the clear-sky irradiance is multiplied by a cloud modification factor (CMF) that accounts for the attenuation of UV radiation (UVR) by clouds and nonabsorbing aerosols. The CMFs are derived from the measured reflectance at $360 \mathrm{~nm}$, assuming that clouds are non- absorbing and their optical depth is independent of wavelength. Estimate of UVR are corrected for the effects of absorbing aerosols by applying a correction factor $C_{\mathrm{a}}$ as described by Arola et al. (2009). $C_{\mathrm{a}}$ typically ranges between 0.96 and 1.00 for the locations considered here.

OMI UV data were downloaded on 18 July 2014 from http://avdc.gsfc.nasa.gov/index.php?site $=595385375 \&$ id $=$ 79. According to the files' header, the data set is referenced as "EOS Aura OMI OMUVB (Collection 3, PGE v1.3; for ascending orbit only with SZA $<88)$ ". These "overpass" data are provided by NASA's Aura Validation Data Center (AVDC) by filtering Level 2 OMUVB data for over 250 ground stations where regular surface UV measurements are performed. Additional OMI UV products are available from the website http://omi.fmi.fi/products.html but these were not used for this study.

The OMI data files provide both $E_{\text {er }}$ (in units of $\mathrm{mW} \mathrm{m}^{-2}$ ) and the UVI. Because the numerical precision of $E_{\mathrm{er}}$ is larger than that of the UVI (which is rounded to one decimal place), we used $E_{\text {er }}$, and divided the ground-based UVI measurements with $k_{\text {er }}$ before comparing with the OMI data sets. The low precision of the native OMI UVI data is a particular problem for Arctic locations where the UVI is frequently smaller than 1.

OMI overpass files contain several UV data products (Table 1). Data products (DP) assessed in the present paper include (1) the "Overpass Erythemal Dose Rate"; the (2) "Erythemal Daily Dose Rate"; (3) the "Clear Sky Erythemal Daily Dose Rate"; (4) the "Erythemal Daily Dose"; and (5) the "Clear Sky Erythemal Daily Dose".

DP (1) is the erythemally weighted irradiance at the time of the satellite overpass. DP (2) is the erythemally weighted irradiance at local solar noon that is calculated from DP (1) by taking the difference of the SZA between the time of local solar noon and the time of the satellite overpass into account. The calculations assume that TOC and COD remain constant between the two times. DP (3) equals DP (2) without the CMF being applied. DP (4) is determined from the measured TOC and COD at the time of the overpass and the assumption that TOC and COD remain constant throughout the day. DP (5) equals DP (4) without the CMF being applied.

Data files contain additional information on data quality; SZA; viewing zenith angle (VZA); horizontal distance between the center of the OMI pixel (defined by the OMI Cross Track Position or CTP) and the nominal location (Dis); the value of the OMI surface albedo climatology used in the retrieval algorithm (SufAlbedo); Lambertian equivalent reflectivity (LambEquRef); terrain height (TerrHgt); and the COD estimated by the OMI UV algorithm (CldOpt). Some of these parameters were used for filtering the data sets when comparing with ground-based data. Because of the challenges to distinguish between high surface albedo and clouds from space, the method of selecting clear-sky data by filtering for $\mathrm{CldOpt}=0$ may not be accurate. 
Table 1. OMI data products assessed in the present paper.

\begin{tabular}{|c|c|c|c|}
\hline Reference & Data product & Acronym & Unit \\
\hline DP (1) & $\begin{array}{l}\text { Overpass Erythemal Dose Rate } \\
\text { (Satellite Measured Overpass UV Index) }\end{array}$ & $\begin{array}{l}\text { OPEDRate } \\
\text { OPUVindex }\end{array}$ & $\begin{array}{l}\mathrm{mW} \mathrm{m}^{-2} \\
\text { Dimensionless }\end{array}$ \\
\hline DP (2) & $\begin{array}{l}\text { Erythemal Daily Dose Rate } \\
\text { (Local Noon Time UV Index) }\end{array}$ & $\begin{array}{l}\text { EDRate } \\
\text { UVindex }\end{array}$ & $\begin{array}{l}\mathrm{mW} \mathrm{m}^{-2} \\
\text { Dimensionless }\end{array}$ \\
\hline DP (3) & $\begin{array}{l}\text { Clear Sky Erythemal Daily Dose Rate } \\
\text { (Local Noon Time Clear Sky UV Index) }\end{array}$ & $\begin{array}{l}\text { CSEDRate } \\
\text { CSUVindex }\end{array}$ & $\begin{array}{l}\mathrm{mW} \mathrm{m}^{-2} \\
\text { Dimensionless }\end{array}$ \\
\hline DP (4) & Erythemal Daily Dose & EDDose & $\mathrm{J} \mathrm{m}^{-2}$ \\
\hline $\mathrm{DP}(5)$ & Clear Sky Erythemal Daily Dose & CSEDDose & $\mathrm{J} \mathrm{m}^{-2}$ \\
\hline
\end{tabular}

At low latitudes, OMI measurements are nominally made once a day in the afternoon around 13:45 local solar time. At high latitudes, there is more than one satellite overpass per day. In these cases, the daily values of DPs (2)-(5) were averaged before comparing with ground-based data. When satellite data were filtered using some of the parameters mentioned above the number of data records contributing to the daily average is reduced to one in most cases.

OMI overpass data files include data for Dis $<180 \mathrm{~km}$. In particular for stations that are located close to the coast or situated on a mountain, the actual albedo as well as the albedo value SufAlbedo used in the OMI surface UV algorithm can change greatly over this distance. Figure 3 shows SufAlbedo for all ground stations extracted from the OMI data files. SufAlbedo is plotted for all data (black symbols) and data where Dis is either smaller than $12 \mathrm{~km}$ (blue symbols) or $5 \mathrm{~km}$ (red symbols). As can be seen from Fig. 3, values of SufAlbedo close to the station can differ substantially (e.g., by up to 0.65 during winter and spring at Finse and Ny-Ålesund) from values farther away. At Eureka, the albedo away from the station is biased high compared to values in close proximity. When the data set is filtered for Dis $<12 \mathrm{~km}$, values of SufAlbedo for a given day of the year are clustered to within \pm 0.05 for all sites but Finse. This site exhibits a bimodal distribution that even persist when the maximum distance is reduced to $5 \mathrm{~km}$ because adjacent pixels of the OMI albedo climatology have greatly different albedo values. For validating OMI, ideally only data should be used where the center of the OMI pixel is close to the ground station. However, by choosing a small value, the number of match-up data points is greatly reduced and the statistics of the comparison become less certain. Based on the results shown in Fig. 3, data were filtered for a maximum distance of $12 \mathrm{~km}$, which we believe to be a good compromise.

\section{Validation method}

Ground-based data were linearly interpolated to either the time of the satellite overpass (DP 1) or local solar noon
(DP 2 and 3). Daily dose data (DP 4 and 5) did not require interpolation. Data were not used when the time between ground and satellite data was larger than the "maximum time" $t_{\mathrm{m}}$. Sites that use multi-filter instruments typically provide a UVI measurement every minute. The maximum time difference for these sites is usually $30 \mathrm{~s}$ and $t_{\mathrm{m}}$ was set to 5 min. Sites equipped with spectroradiometers provide measurements with a frequency ranging from one to four scans per hour. Typical time differences between ground and satellite data for these sites therefore range between 7.5 (Barrow and Summit) and $30 \mathrm{~min}$ (Sodankylä and Jokioinen). $t_{\mathrm{m}}$ was set to $30 \mathrm{~min}$ for Alert, Eureka, Resolute, Barrow, and Summit, and to 60 min for Sodankylä and Jokioinen.

To allow a comparison of results from this study to those by T07, similar metrics were used to quantify differences between the OMI and ground-based data sets. These are

- $\rho_{i}=E_{\mathrm{s}, i} / E_{\mathrm{g}, i}$ : ratio of satellite-derived data $E_{\mathrm{s}, i}$ and ground-based data $E_{\mathrm{g}, i}$, where the index $i$ indicates the data product $(i=1,2,3,4,5)$. Both $E_{\mathrm{s}, i}$ and $E_{\mathrm{g}, i}$ indicate "match-up" data for a particular record of the OMI data file. The quantity $\rho_{i}$ defines a distribution, which in most cases cannot be well represented by a normal distribution. The statistics defined below were calculated both from monthly and annual distributions of $\rho_{i}$. These monthly and annual statistics include all years when data are available. Potential temporal drifts of the OMI data set were assessed with data from Summit, the site with the least cloud influence. A linear regression fitted to a time series of the ratio of OMI and ground overpass data (DP 1) revealed a statistically insignificant drift of $0.07 \pm 0.11 \%( \pm 2 \sigma)$ per year. The absence of drifts was further confirmed by analyzing monthly average data.

- $N_{i}$ : the number of $\rho_{i}$ contributing to the statistics of a given month or the year.

- $\bar{\rho}_{i}:$ the average of $\rho_{i}$.

- $\widetilde{\rho}_{i}:$ the median of $\rho_{i}$. 

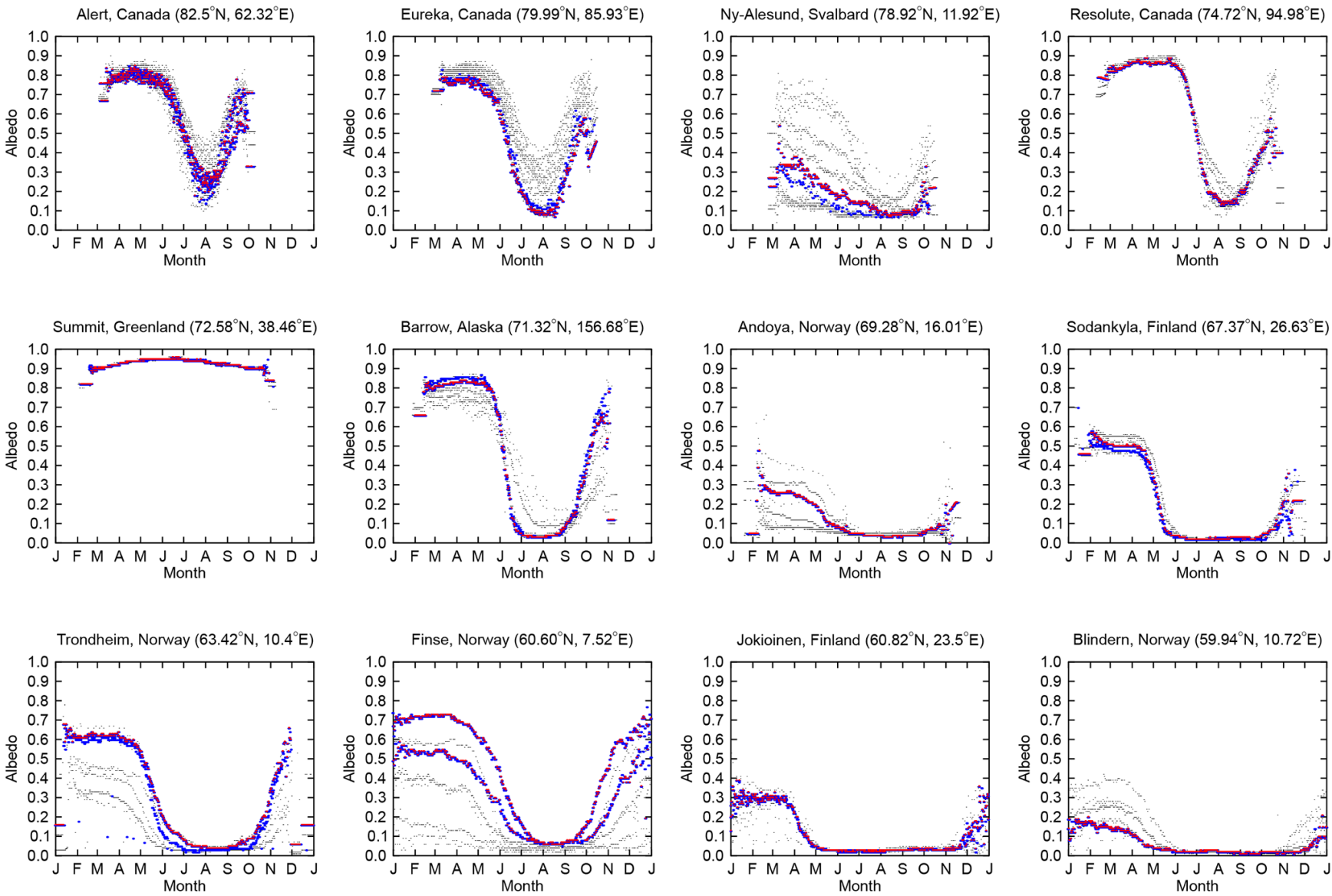

Figure 3. Surface albedo (SufAlbedo) of the OMI albedo climatology for each site, extracted from the OMI data files. Black symbols indicate all available data. Blue symbols indicate data where the distance (parameter "Dis") between the location of the stations and the center of the OMI pixel is smaller than $12 \mathrm{~km}$. For red symbols, Dis is smaller than $5 \mathrm{~km}$.

- $\operatorname{Min}_{i}$ and $\operatorname{Max}_{i}$ : the minimum and maximum values of $\rho_{i}$.

- $p_{f, i}$ : the ratio at the $f$ th-percentile with $f=5,25$, 75 , and 95 . For example, $p_{25,2}$ is the ratio at the 25 th percentile of the $\rho_{2}$ distribution pertaining to DP (2). The difference between $p_{25, i}$ and $p_{75, i}$ is called the "interquartile range."

- $W_{10, i}, W_{20, i}, W_{30, i}:$ percentage of satellite-derived data that agree to within 10,20 , and $30 \%$, respectively, with ground-based data.

As an alternative approach to quantifying the difference between OMI and ground data, we also calculated the monthly average from both data sets, and ratioed these averages:

$R_{i}(y, m) \equiv \frac{\sum E_{\mathrm{s}, i}(y, m)}{\sum E_{\mathrm{g}, i}(y, m)}$,

where the summations are over all data within a given year $y$ and month $m$, provided that both satellite and ground-based measurements are available. For each month, ratios $R_{i}(y, m)$ of all years were averaged and the resulting average is denoted $\bar{R}_{i}$. When at least 5 years of data were available, also the standard deviation $\sigma_{i}$ was calculated from the 5-9 annual values, allowing to quantify the variability of $R_{i}(y, m)$ from year to year. To avoid artifacts caused by data gaps when calculating monthly averages, only months with at least 20 days of data were considered. Despite this restriction, there could still be a bias in the monthly average if periods with missing days are not equally distributed in every year. For example, solar radiation tends to increase during months in the spring because the noontime SZA decreases. If measurements are missing at the beginning of a month, the monthly average will be biased high. To correct for this effect, the method developed by Bernhard (2011) was applied.

\section{Results}

As part of the analysis, the ratio and difference of OMI and ground UVI data were plotted for each site as functions of time, the UVI measured at the ground, and the day of the 
year. Furthermore, correlations between OMI and groundbased data were calculated and frequency distributions of $\mathrm{OMI} /$ ground ratios were plotted for each month. This analysis was repeated for the five data products discussed in Sect. 3. The resulting wealth of information exceeds the space of this paper; however, the resulting plots and statistics are available as supplements: for each site and data product, a PDF page in a standardized format is provided. An annotated example of such a page is provided in Appendix A.

Because the values of $\rho_{i}$ are not normal distributed and change greatly from month to month at some locations, box-whisker plots were chosen to visualize the results. Figure 4 shows these plots for DP (4). Data were filtered for $\mathrm{SZA}<84^{\circ}$ and Dis $<12 \mathrm{~km}$. (The SZA was restricted to avoid that data affected by instrument noise skew the statistics. For SZA $>84^{\circ}$, the UVI is typically smaller than 0.2 and systematic errors at this low intensity are of little relevance.) Figure 4 indicates for each site and month the statistics $\bar{\rho}_{4}, \widetilde{\rho}_{4}, p_{5,4}, p_{25,4}, p_{75,4}$, and $p_{95,4}$. Statistics for the entire year are indicated as the 13th month. Table 2 shows the comparison in tabular form. Two months were chosen for each site for this table: a month in spring when the surface is covered by snow and a month in summer when it is snow free. These months were selected based on the albedo climatology of Fig. 3. The OMI albedo climatology is invariant from year to year and therefore does not capture variability caused by the timing of snow melt. It can therefore be expected that $\rho_{i}$ shows the highest variability in the "transition" months when snow melt occurs. On the other hand, for the "high winter" and "mid-summer" months chosen for Table 2, a static albedo climatology is conceivably sufficient for accurate UVI retrievals from space-based observations.

Figure 4 and Table 2 indicate large systematic differences between OMI and ground data at some sites and for some months. For example, $\widetilde{\rho}_{4}$ is 0.60 between March and May at Ny-Ålesund, 1.55 in February and March at Trondheim, and smaller than 0.5 between January and April at Finse. On the other hand, the agreement between the two data sets is excellent at Summit and Sondakylä for all months. Good agreement is also observed during spring at Alert, Eureka, Resolute, and Barrow, and during summer at $\mathrm{Ny}$ Ålesund, Finse, Jokioinen and Blindern. In Andøya and southern Scandinavian sites, the variability of the difference between OMI and ground daily doses is large as evidenced by the large interquartile range (e.g., Andøya in summer) and large whiskers (e.g., Blindern in fall). The possible reasons for the observed systematic differences and variations between space- and ground-based observations are discussed in Sect. 5.

Figure 5 shows box-whisker plots and validation statistics for overpass erythemal dose rate (DP 1). A table similar to Table 2 but for DP (1) instead of DP (4) is available in the Supplement. These data were again filtered for SZA $<84^{\circ}$ and Dis $<12 \mathrm{~km}$. By comparing Fig. 4 with Fig. 5 it can be seen that the distributions for DP (1) (as indicated by the in- terquartile range and the length of the whiskers) are generally much wider than those for DP (4) discussed earlier.

We will show in the following that the different results for DP (1) and DP (4) are a consequence of the different sampling and averaging schemes of ground and satellite data.

Ground measurements are a point measurement, whereas OMI provides the mean surface UV over a large area $\left(13 \times 24 \mathrm{~km}^{2}\right.$ (along $\times$ across track) in nadir direction and increasing to $13 \times 128 \mathrm{~km}^{2}$ at the most outer swathangle of $57^{\circ}$ (http://www.knmi.nl/omi/research/instrument/ characteristics.php)). The variability of the erythemal dose rate over the area of the OMI pixel is averaged in OMI data, while ground measurements capture these fluctuations. Hence, the ratio of OMI/ground is also affected by this variability, leading to the wide distributions evident in Fig. 5. The effect is largest at sites with high cloud variability and smallest at sites or seasons where clouds are either infrequent (e.g., Resolute in July) or where the attenuation of UVR by clouds is reduced by high surface albedo (e.g., Alert in spring, Summit all year). This reduction is the result of multiple scattering between the surface and cloud ceiling, which effectively traps light (e.g., Nichol et al., 2003).

As discussed in Sect. 1, the daily dose of ground measurements is calculated from the individual measurements performed throughout the day, while the OMI UV algorithm assumes that the TOC and COD remain constant. The difference in sampling will result in variability in the ratio of the two data sets. The comparison of Fig. 4 with Fig. 5 suggests that the uncertainty of the OMI-derived erythemal daily dose introduced by the assumption of constant TOC and COD is smaller than the uncertainty in the OMI overpass erythemal dose rate applicable to a specific location that is caused by the variability of this dose rate over the area of the OMI pixel.

The comparison of OMI and ground overpass erythemal dose rate data was repeated without filtering these data for SZA $<84^{\circ}$ and Dis $<12 \mathrm{~km}$. As expected, distributions calculated without the filter were considerably larger than those obtained with the filter. These data are part of the Supplement.

Figure 6 is based on DP (4) and compares the average $\bar{\rho}_{4}$ and median $\widetilde{\rho}_{4}$ of the match-up statistics discussed earlier with the average ratio $\bar{R}_{4}$ derived from the monthly average daily doses. The median $\widetilde{\rho}_{4}$ agrees well with $\bar{R}_{4}$ for all sites and months, suggesting that $\widetilde{\rho}_{4}$ is an appropriate statistical quantity to assess systematic biases between OMI and ground data. The average $\bar{\rho}_{4}$ is less appropriate for this assessment because it is more affected by the skewness of $\rho_{4}$ distributions. As explained in Sect. 3, the year-to-year variability of the OMI/ground ratios is quantified with $\sigma_{4}$ and this standard deviation is indicated by error bars in Fig. 6 . At some sites (e.g., Summit, Sondankylä), the error bars are smaller than the size of the symbol, highlighting that the bias between OMI and ground data is nearly constant over time. At high-Arctic sites, $\sigma_{4}$ is typically small in March and April when the ground is covered by snow in all years. Similarly, 

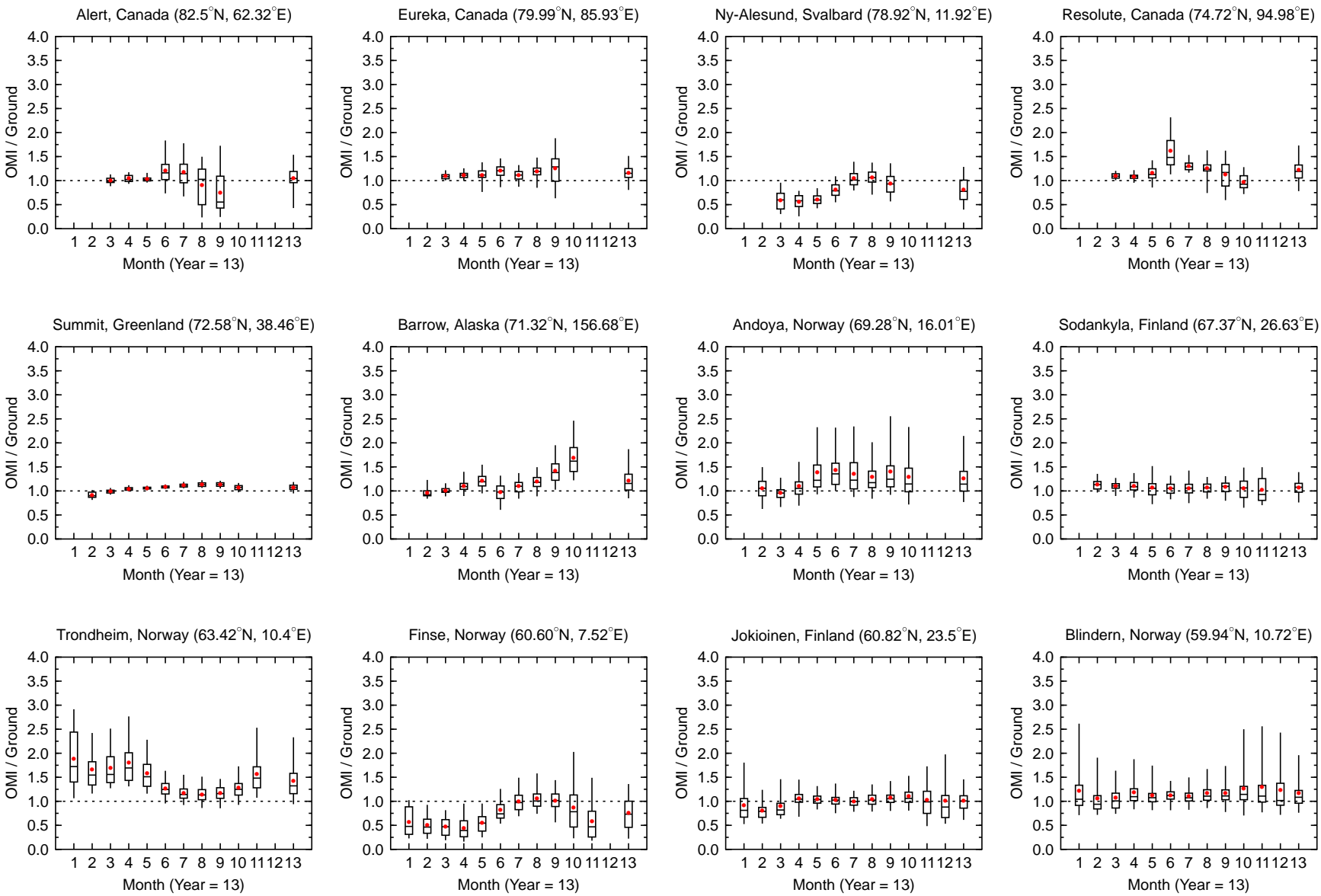

Figure 4. Ratio of the erythemal daily dose (DP 4) measured by OMI and ground stations for each site. The box-whisker plots indicate for each month the 5th and 95th percentiles (whisker), the interquartile range (box), median (line), and average (red dot). Statistics based on annual data are indicated as the 13th month. Match-up data were filtered for SZA $<84^{\circ}$ and Dis $<12 \mathrm{~km}$.

$\sigma_{4}$ is small during summer at Scandinavian sites when the ground is snow free. As can be expected, $\sigma_{4}$ is largest in the transition months when the surface becomes snow free (e.g., June at Alert and Barrow, April at Finse) or when snow starts to accumulate again after the summer (e.g., September at Alert, October at Barrow).

All results presented above were based on the ratio of OMI and ground data. For the large SZAs prevailing at high latitudes early in spring or late in fall, even large relative differences between the two data sets have only a small effect (with arguably negligible consequences) on absolute UVR levels. To emphasize this point, Fig. 7 shows box-whisker plots of the difference of OMI and ground UVI measurements for the time of the satellite overpass. Statistics (i.e., whiskers, interquartile range, median, and average) were calculated the same way as for the analysis of ratios shown in Fig. 5. With few exceptions, the 25th and 75th percentiles of the difference do not exceed \pm 1 UVI unit. Exceptions include June at Resolute (median bias of 1.0 UVI units), and April and May at Trondheim (bias of 1.2) and Finse (bias of -2.1).

\section{Discussion}

The effect of unrealistic albedo can either lead to a positive or negative bias of OMI UV data because the albedo is a key parameter when calculating the CMF. When the OMI parameter SufAlbedo exceeds the actual albedo ("Case 1"), the OMI UV algorithm interprets reflectance from clouds as reflectance from the surface and sets CldOpt to 0 , resulting in $\mathrm{CMF}=1$. This has two effects, which both lead to a positive bias of OMI data. First, a high value of SufAlbedo leads to a high value of the derived clear-sky irradiance (e.g., Fig. 2). Second, since $\mathrm{CMF}=1$, the irradiance returned by the OMI UV algorithm is not reduced by cloud attenuation, in contrast to the irradiance seen by the instrument at the surface. High values of SufAlbedo lead to an inconsistency when there are no clouds: in this case, the reflectance measured by the satellite is lower than that expected from the high value of $\mathrm{Su}$ fAlbedo. This inconsistency could be exploited to improve the OMI albedo climatology. For example, data records with a large difference between the measured (low) reflectance and that expected from the high value of SufAlbedo could 
Table 2. Validation statistics ${ }^{\mathrm{a}}$ for daily erythemal dose (DP 4).

\begin{tabular}{|c|c|c|c|c|c|c|c|c|c|c|c|c|}
\hline Site & Month & Surface $^{\mathrm{b}}$ & $N_{4}$ & $p_{5,4}$ & $p_{25,4}$ & $\widetilde{\rho}_{4}$ & $\bar{\rho}_{4}$ & $p_{75,4}$ & $p_{95,4}$ & $\begin{array}{r}W_{10,4} \\
(\%)\end{array}$ & $\begin{array}{r}W_{20,4} \\
(\%)\end{array}$ & $\begin{array}{r}W_{30,4} \\
(\%)\end{array}$ \\
\hline \multirow[t]{2}{*}{ Alert $\left(82.50^{\circ} \mathrm{N}\right)$} & April & $\mathrm{SC}$ & 74 & 0.93 & 0.98 & 1.02 & 1.04 & 1.11 & 1.17 & 73 & 96 & 99 \\
\hline & July & SF & 97 & 0.67 & 0.95 & 1.14 & 1.17 & 1.34 & 1.78 & 31 & 47 & 65 \\
\hline \multirow[t]{2}{*}{ Eureka $\left(79.99^{\circ} \mathrm{N}\right)$} & April & $\mathrm{SC}$ & 49 & 0.99 & 1.06 & 1.11 & 1.12 & 1.15 & 1.26 & 41 & 92 & 96 \\
\hline & July & SF & 166 & 0.87 & 1.03 & 1.12 & 1.11 & 1.19 & 1.32 & 34 & 73 & 91 \\
\hline \multirow[t]{2}{*}{ Ny-Ålesund $\left(78.92^{\circ} \mathrm{N}\right)$} & April & $\mathrm{SC}$ & 213 & 0.26 & 0.46 & 0.58 & 0.56 & 0.69 & 0.79 & 0 & 2 & 7 \\
\hline & August & SF & 196 & 0.71 & 0.97 & 1.06 & 1.07 & 1.18 & 1.37 & 40 & 66 & 82 \\
\hline \multirow[t]{2}{*}{ Resolute $\left(74.72^{\circ} \mathrm{N}\right)$} & April & $\mathrm{SC}$ & 72 & 0.95 & 1.05 & 1.09 & 1.08 & 1.11 & 1.22 & 58 & 92 & 99 \\
\hline & August & SF & 96 & 0.74 & 1.20 & 1.24 & 1.25 & 1.33 & 1.63 & 7 & 16 & 63 \\
\hline \multirow[t]{2}{*}{ Summit $\left(72.58^{\circ} \mathrm{N}\right)$} & March & PSC & 155 & 0.92 & 0.96 & 0.99 & 0.99 & 1.02 & 1.06 & 98 & 100 & 100 \\
\hline & July & PSC & 128 & 1.06 & 1.08 & 1.11 & 1.11 & 1.14 & 1.19 & 44 & 96 & 100 \\
\hline \multirow[t]{2}{*}{ Barrow $\left(71.32^{\circ} \mathrm{N}\right)$} & March & $\mathrm{SC}$ & 100 & 0.89 & 0.97 & 0.99 & 1.01 & 1.05 & 1.16 & 79 & 96 & 98 \\
\hline & July & $\mathrm{SF}$ & 180 & 0.84 & 0.98 & 1.10 & 1.10 & 1.18 & 1.37 & 38 & 74 & 88 \\
\hline \multirow[t]{2}{*}{ Andøya $\left(69.28^{\circ} \mathrm{N}\right)$} & March & $\mathrm{SC}$ & 186 & 0.67 & 0.87 & 0.96 & 0.97 & 1.03 & 1.28 & 48 & 72 & 83 \\
\hline & August & SF & 175 & 0.84 & 1.07 & 1.17 & 1.29 & 1.41 & 2.01 & 26 & 51 & 61 \\
\hline \multirow[t]{2}{*}{ Sodankylä $\left(67.37^{\circ} \mathrm{N}\right)$} & March & $\mathrm{SC}$ & 116 & 0.90 & 1.06 & 1.11 & 1.10 & 1.15 & 1.27 & 41 & 87 & 97 \\
\hline & August & SF & 136 & 0.84 & 0.98 & 1.06 & 1.07 & 1.14 & 1.29 & 53 & 82 & 93 \\
\hline \multirow[t]{2}{*}{ Trondheim $\left(63.42^{\circ} \mathrm{N}\right)$} & March & $\mathrm{SC}$ & 166 & 1.27 & 1.39 & 1.56 & 1.70 & 1.93 & 2.51 & 1 & 2 & 10 \\
\hline & August & SF & 182 & 0.86 & 1.03 & 1.13 & 1.15 & 1.24 & 1.51 & 29 & 64 & 82 \\
\hline \multirow[t]{2}{*}{ Finse $\left(60.60^{\circ} \mathrm{N}\right)$} & March & $\mathrm{SC}$ & 104 & 0.19 & 0.29 & 0.47 & 0.47 & 0.62 & 0.82 & 2 & 5 & 11 \\
\hline & August & $\mathrm{SF}$ & 152 & 0.74 & 0.90 & 1.01 & 1.06 & 1.15 & 1.58 & 43 & 65 & 79 \\
\hline \multirow[t]{2}{*}{ Jokioinen $\left(60.82^{\circ} \mathrm{N}\right)$} & February & $\mathrm{SC}$ & 125 & 0.54 & 0.67 & 0.79 & 0.80 & 0.87 & 1.24 & 10 & 29 & 50 \\
\hline & July & $\mathrm{SF}$ & 164 & 0.78 & 0.92 & 0.99 & 1.00 & 1.07 & 1.22 & 53 & 84 & 93 \\
\hline \multirow[t]{2}{*}{ Østerås $\left(59.95^{\circ} \mathrm{N}\right)$} & February & $\mathrm{SC}$ & 166 & 0.67 & 0.80 & 0.89 & 0.97 & 1.08 & 1.50 & 23 & 54 & 70 \\
\hline & July & $\mathrm{SF}$ & 166 & 0.78 & 0.99 & 1.07 & 1.12 & 1.20 & 1.55 & 46 & 68 & 81 \\
\hline \multirow[t]{2}{*}{ Blindern $\left(59.94^{\circ} \mathrm{N}\right)$} & February & $\mathrm{SC}$ & 160 & 0.72 & 0.84 & 0.94 & 1.06 & 1.12 & 1.91 & 26 & 57 & 75 \\
\hline & July & SF & 163 & 0.82 & 1.01 & 1.07 & 1.10 & 1.17 & 1.50 & 48 & 72 & 86 \\
\hline
\end{tabular}

${ }^{a}$ Match-up data were filtered for SZA $<84^{\circ}$ and Dis; $12 \mathrm{~km} .{ }^{\mathrm{b}} \mathrm{SC}=$ snow cover, $\mathrm{SF}=$ snow-free, $\mathrm{PSC}=$ permanent snow cover.

be selected for each grid point, and the albedo climatology could be adjusted until the difference disappears.

If SufAlbedo greatly underestimates the actual albedo ("Case 2"), reflectance from the surface is assumed to be caused by clouds, and the cloud optical depth is set to a value larger than 0 , resulting in $\mathrm{CMF}<1$. This has two effects, which both lead to a negative bias of OMI data. First, a low value of SufAlbedo leads to a low value of the derived clear-sky irradiance. Second, since CMF is smaller than 1, the irradiance returned by the OMI UV algorithm is further reduced. In contrast to Case 1, no inconsistencies can occur because high reflectance from snow measured during clear skies can always (albeit incorrectly) be interpreted as cloud reflectance.

Examples of Cases 1 and 2 are provided in Sect. 5.1 when discussing results from the various sites.

During periods of scattered clouds, the UV irradiance at the surface can exceed the clear-sky irradiance (e.g., Mims III and Frederick, 1994). Such enhancements occur when the solar disk is not obstructed, while clouds in the vicinity of the Sun increase the diffuse component over the value for clear skies. High surface albedo may increase this effect further (Bernhard et al., 2010). The OMI UV algorithm does not ac- count for this effect and this omission may contribute to negative biases for overpass data (DP 1) when scattered clouds are present. The magnitude of the effect is modest, however, because cloud enhancements of the UVI by more than $10 \%$ are very rare in the Arctic (e.g., Bernhard et al., 2007, 2008), and also the frequency of enhancements between 0 and $10 \%$ is typically small (e.g., less than $12 \%$ of all measurements at Summit (Bernhard et al., 2008) and even less at sites where overcast skies are the norm, such as Barrow in the fall; Bernhard et al., 2007).

It was anticipated that comparisons for overpass data show the least variability because this data product provides the best temporal match between satellite- and ground-based observations. Our results refute this hypothesis. The least variation was instead observed for the daily erythemal dose. The reason for this finding is likely due to ergodicity: for spacebased observations, the variation introduced by clouds is spatially averaged over the area of the pixel, while the temporal integration of ground-based measurements performed over the course of the day "smoothes" out cloud effects. The effects of spatial and temporal averaging seem to be similar. 

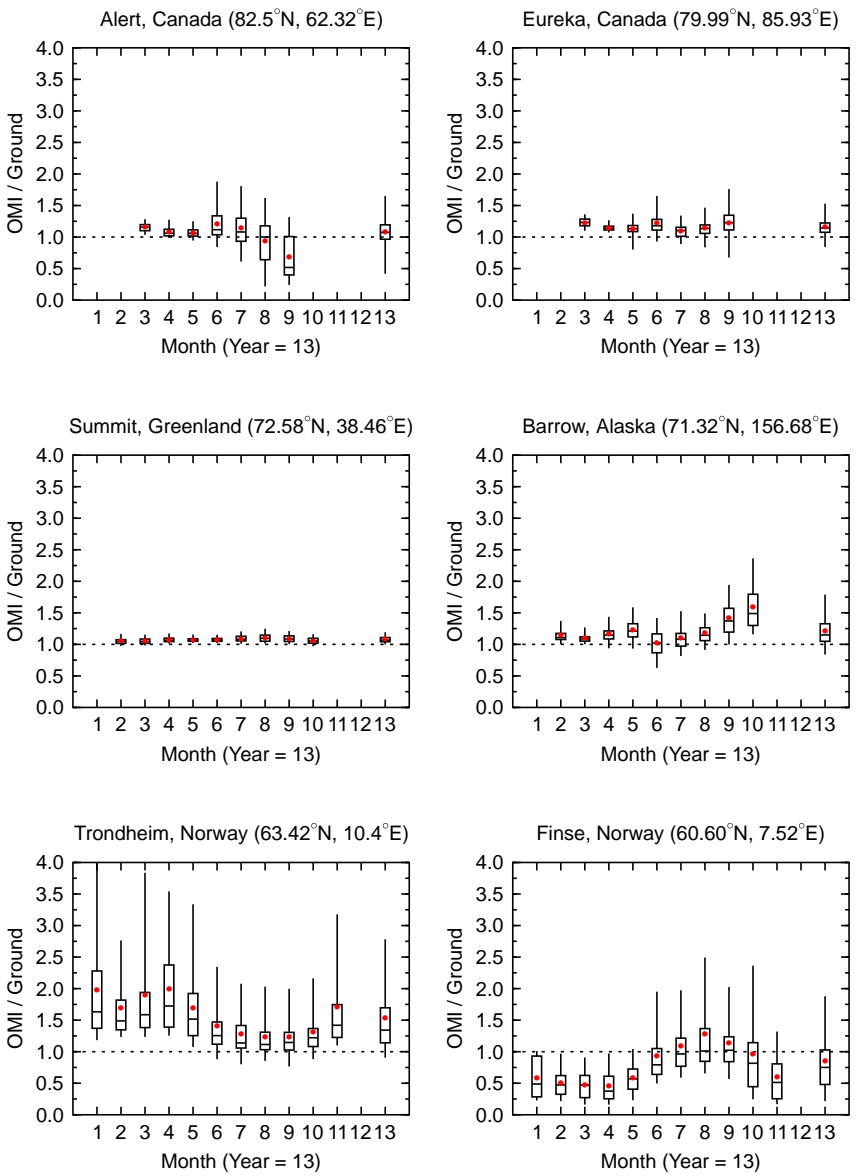

Figure 5. Same as Fig. 4 but for overpass erythemal dose rate (DP 1).

\subsection{Discussion by site}

Results from each site are briefly discussed below, with the exception of Summit, Barrow, and Trondheim, for which more elaborate analyses are presented. Measurements from Summit and Barrow are completed with radiative transfer calculations, which are used for the interpretation of the difference of ground and satellite data. For Barrow, measurements of surface albedo and COD are also available and were used for interpretation. For other sites, the actual surface albedo was estimated from snow depth information. Measurements from Trondheim are used to study the Case 1 mechanism in more detail. If not otherwise noted, systematic differences or "biases" discussed below refer to $\widetilde{\rho}_{4}$ and are expressed in percent (e.g., $\widetilde{\rho}_{4}=1.05$ corresponds to a bias of $+5 \%)$.

\subsubsection{Alert, Canada}

Alert is located close to the northernmost point of Canada. The bias for April and May (when SufAlbedo is about 0.8; Fig. 3 ) is less than $2 \%$. According to Canadian Climate Normals (CCN; http://climate.weather.gc.ca/climate_normals/),
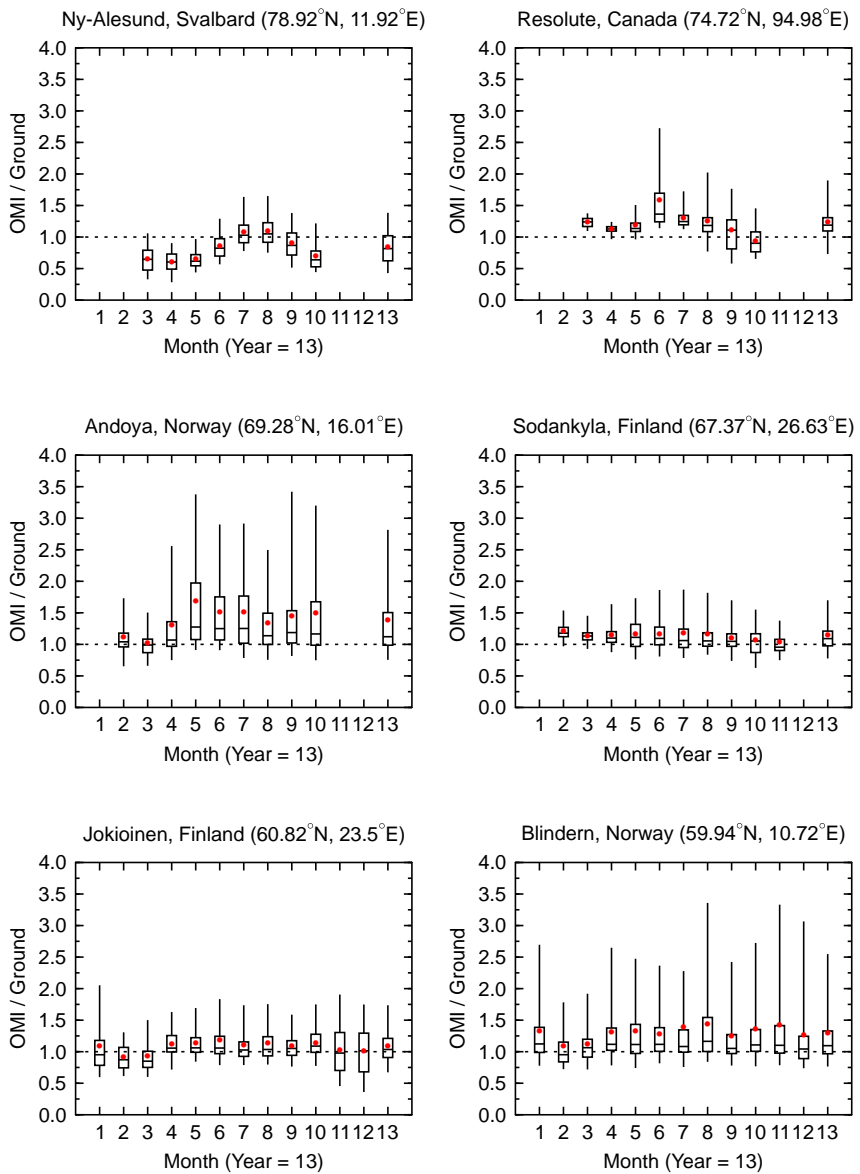

the ground at Alert is covered by more than $10 \mathrm{~cm}$ of snow at all days during these months. Results from Barrow (Sect. 5.1.6), which is an Arctic coastal site like Alert, indicate that an albedo of 0.8 is a reasonable value for these conditions. In June and July, the bias is about $15 \%$. SufAlbedo decreases from 0.75 to 0.25 during this period, which is likely too large considering that less than two days in July have a snow depth of $2 \mathrm{~cm}$ or larger. Variability of $\rho_{4}$ is relatively high in the summer and fall when the surface is snow free. For example, the interquartile range is $0.99-1.05$ in May, but $0.95-1.34$ in July.

\subsubsection{Eureka, Canada}

Eureka is about $480 \mathrm{~km}$ southwest of Alert. OMI data are biased high by about $11 \%$ between March and May when SufAlbedo is about 0.75 . According to $\mathrm{CCN}$, not all days during this period have snow cover in excess of $5 \mathrm{~cm}$. The albedo value used by the OMI UV algorithm is therefore likely too large, which may explain the positive bias. The ground in July and August is virtually snow free (suggesting an albedo of less than 0.05 (Blumthaler and Ambach, 1988)), while SufAlbedo is between 0.1 and 0.2. Figure 2 suggest that up to 

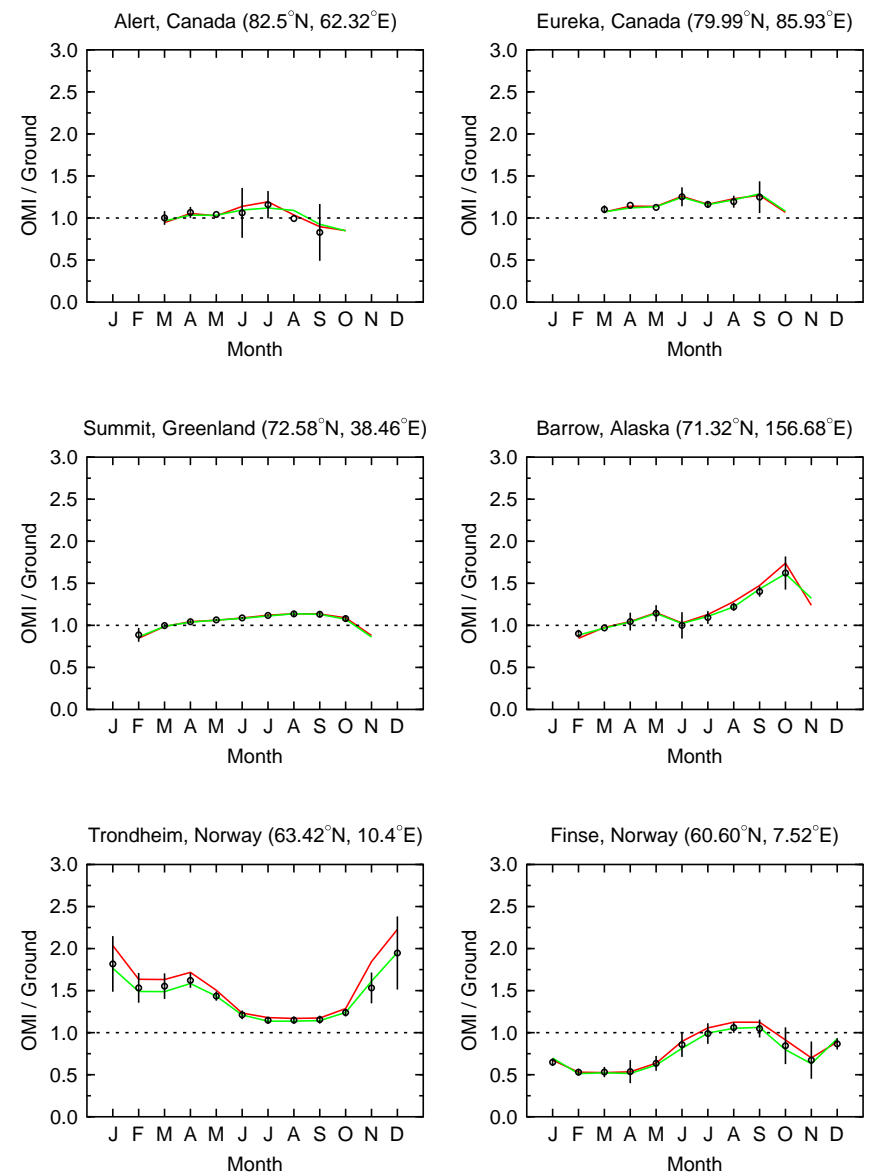
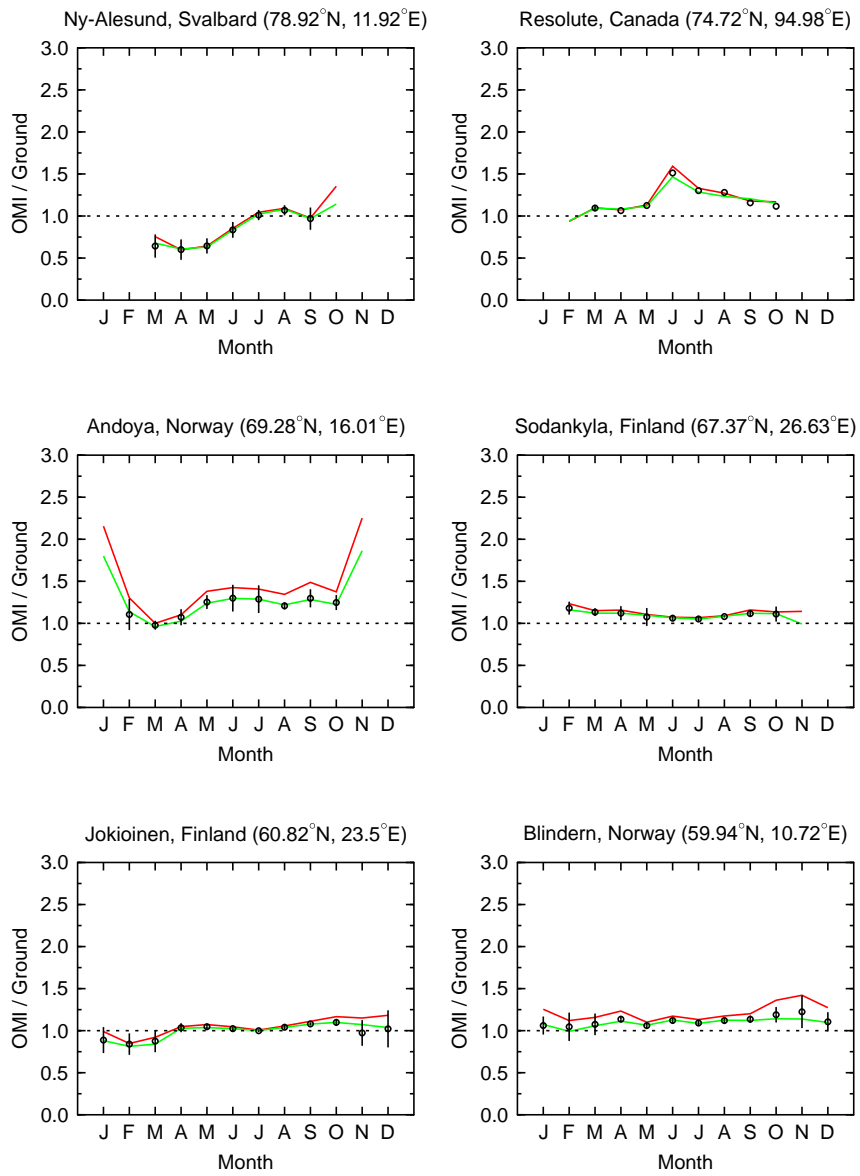

Figure 6. Comparison of $\bar{\rho}_{4}$ (red lines), $\widetilde{\rho}_{4}$ (green lines), and $\bar{R}_{4}$ (open circles). The error bars indicate $\pm \sigma_{4}$. Data used for this figure were not filtered for SZA and Dis because such filtering would have reduced the number of data points of $\bar{R}_{4}$ substantially. Values of $\bar{\rho}_{4}$ and $\widetilde{\rho}_{4}$ are therefore slightly different from those indicated in Fig. 4.

$10 \%$ of the of the bias of $12-19 \%$ observed during these months could be caused by the relatively large values of $\mathrm{Su}$ fAlbedo applied during these month.

\subsubsection{Ny-Ålesund, Svalbard}

Ny-Ålesund is at the western side of the Svalbard archipelago. Despite its high northern latitude, the climate is relatively mild because of the influence of the Gulf Stream. The bias at Ny-Ålesund between March and May is $-40 \%$. SufAlbedo decreases from 0.35 to 0.20 during this period, which is likely far too low considering that snow cover at this time typically exceeds $50 \mathrm{~cm}$. The underestimate is an example of the Case 2 mechanism discussed above. During July and August, when SufAlbedo is less than 0.15 and the ground is snow free, the bias is less than $6 \%$, confirming that OMI data are quite accurate when the albedo is accurately specified.

\subsubsection{Resolute, Canada}

Resolute is located about $600 \mathrm{~km}$ south of Eureka. Complete years of ground-based measurements at Resolute are only available in 2007, 2009, 2010, and 2011. Large data gaps at this site make statistics less robust (e.g., $\sigma_{4}$ could not be calculated for this site). In March and April, when SufAlbedo is 0.85 and snow cover exceeds $10 \mathrm{~cm}$ during more than 28 days per month according to $\mathrm{CCN}$, the bias is $9 \%$, suggesting that the OMI albedo climatology is appropriate. On the other hand, there is a large bias of $48 \%$ and large variability in June, when SufAlbedo drops from 0.85 to 0.5 . CCN data indicate that snow disappears in June and the albedo values used by the OMI UV algorithm are therefore likely too large, explaining the large positive bias (Case 1).

\subsubsection{Summit, Greenland}

Summit is located near the top of the Greenland ice cap and has a very high surface albedo of about 0.97 year round (Bernhard et al., 2008). Because of this high albedo, the influ- 

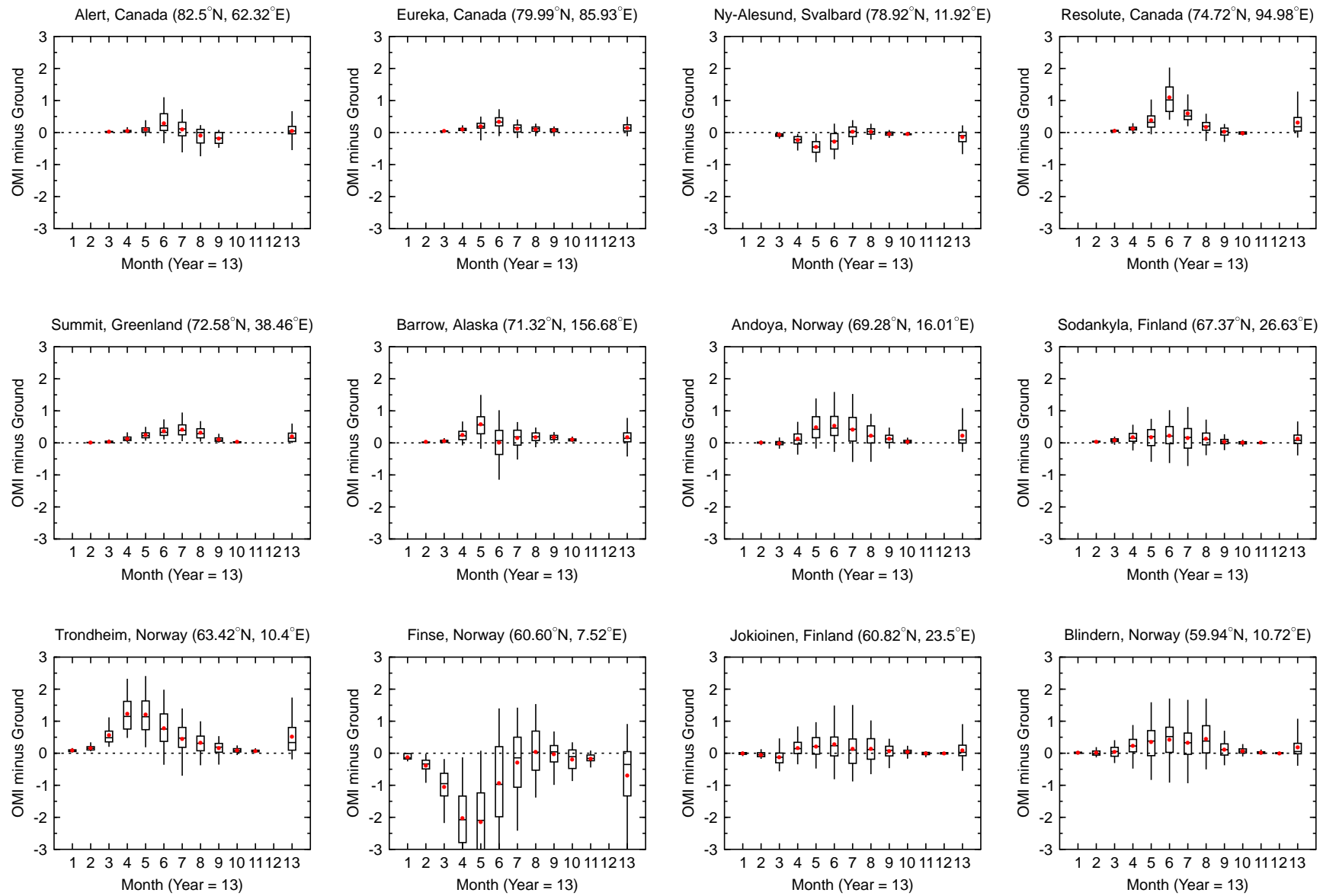

Figure 7. Difference of OMI and ground UVI data, calculated from overpass erythemal dose rate data (DP 1). The box-whisker plots indicate for each month the 5th and 95th percentiles (whisker), the interquartile range (box), median (line), and average (red dot). Statistics based on annual data are indicated as the 13th month. Match-up data were filtered for SZA $<84^{\circ}$ and Dis $<12 \mathrm{~km}$.

ence of clouds is limited: the average attenuation of spectral irradiance at $345 \mathrm{~nm}$ is $3.5 \%$ in spring and $5.8 \%$ in summer (Bernhard et al., 2008). Because of the small cloud effect and constant albedo, the scatter between OMI and ground observations is extremely small.

For sites located above $2500 \mathrm{~m}$ such as Summit, the OMI surface UV algorithm does not apply a cloud correction; i.e., clear-sky conditions are assumed for these altitudes at all times. This has to be taken into consideration when comparing OMI and ground data at Summit.

Figure 8 a compares the medians $\widetilde{\rho}_{1}, \widetilde{\rho}_{2}$, and $\widetilde{\rho}_{4}$ of DP (1), DP (2), and DP (4), respectively. The median $\widetilde{\rho}_{1}$ for DP (1) (which was already shown in Fig. 5) is relatively constant and varies between 1.04 (equal to a bias of $4 \%$ ) in February and March and 1.10 (bias of $10 \%$ ) in August. The median $\widetilde{\rho}_{2}$ and $\widetilde{\rho}_{4}$ for DPs (2) and (4) exhibit increasing tendencies with $\widetilde{\rho}_{2}$ ranging from 0.98 (bias of $-2 \%$ ) in February to 1.14 (bias of $14 \%$ ) in August. The medians $\widetilde{\rho}_{2}$ and $\widetilde{\rho}_{4}$ are rather similar, except for February when $\widetilde{\rho}_{4}$ is 0.90 .

Ground-based measurements at Summit are part of the Version 2 data set of the NSF UV monitoring network (http:
//uv.biospherical.com/Version2/), referred to as "V2 data set" in the following. This data set includes clear-sky model data for every measurement. The availability of these model data presents the opportunity to better understand the reasons of the difference between OMI and ground-based measurements shown in Fig. 8a.

Model data were calculated with the radiative transfer model UVSPEC/libRadtran (Mayer and Kylling, 2005). Model input parameters are described in detail by Bernhard et al. (2008). In brief, parameters include SZA; the extraterrestrial spectrum; atmospheric profiles of air density, temperature, ozone, and aerosol extinction; TOC; surface albedo; atmospheric pressure at station level; aerosol optical depth $\left(\tau_{\mathrm{a}}\right)$; and single scattering albedo for aerosols. The TOC used for modeling was calculated from measured UV spectra according to the method by Bernhard et al. (2003). Surface albedo was set to 0.97 in accordance with measurements by Grenfell et al. (1994). The spectral dependence of $\tau_{\mathrm{a}}$ was parameterized with Ångström's formula: $\tau_{\mathrm{a}}=\beta \lambda^{-\alpha}$. Aerosol optical depth data for Summit are currently not available, and calculations were performed for stratospheric background 


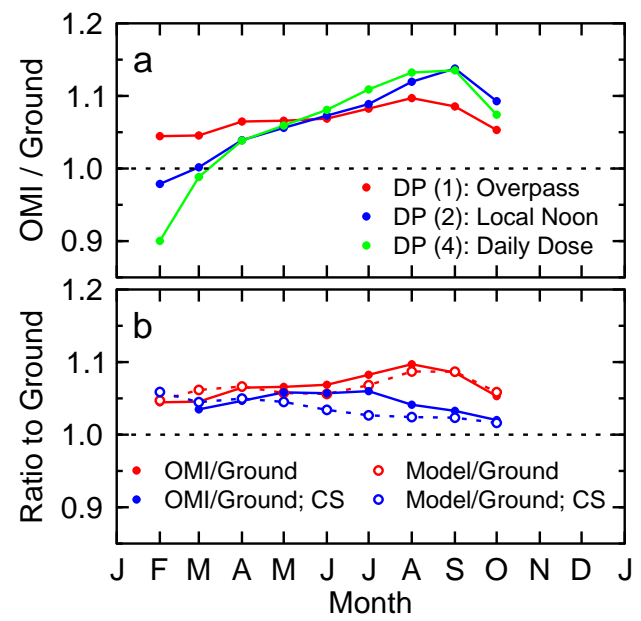

Figure 8. Comparison of OMI and ground data at Summit. Panel a: median ratios $\widetilde{\rho}_{1}, \widetilde{\rho}_{2}$, and $\widetilde{\rho}_{4}$ of DP (1), DP (2), and DP (4), respectively. Panel b: comparison of median ratios $\widetilde{\rho}_{1}$ of OMI and ground overpass measurements (solid symbols) with median ratios of modeled and measured data (open symbols). Results for data filtered for SZA $<84^{\circ}$ and Dis; $12 \mathrm{~km}$ are indicated in red. Results for data that were additionally filtered for clear-sky (CS) conditions are indicated in blue. The two data sets indicated by red solid symbols in Panels $\mathrm{a}$ and $\mathrm{b}$ are identical.

aerosol conditions by setting $\alpha=1.0$ and $\beta=0.008$. This translates to $\tau_{\mathrm{a}}=0.027$ at $300 \mathrm{~nm}$. Actual values of $\tau_{\mathrm{a}}$ are likely larger, in particular during spring when Summit may be affected by Arctic haze (VanCuren et al., 2012). Bernhard et al. (2008) suggest that aerosols may reduce spectral irradiance at $345 \mathrm{~nm}$ by about $1-3 \%$ at Summit. Model data are therefore likely too large by this amount.

Figure $8 \mathrm{~b}$ compares $\widetilde{\rho}_{1}$ (solid red symbols) with the median calculated from the ratio of the model results and the ground-based measurements (open red symbols). The two data sets agree with each other to within $\pm 1.5 \%$ for all months, but are biased high by $4-10 \%$. A bias of this magnitude is not surprising because neither the OMI UV algorithm nor the model take cloud attenuation into account. As mentioned earlier, clouds attenuate on average by $3.5 \%$ between 01 March and 21 June and by $5.8 \%$ between 22 June and 12 October (Bernhard et al., 2008).

Measurements performed during clear skies are flagged in the V2 data set. Clear-sky periods are determined based on temporal variability of measured spectral irradiance at $600 \mathrm{~nm}$ as described by Bernhard et al. (2008). Groundbased, OMI, and model data were filtered for clear-sky periods, the comparisons between the three data sets were repeated, and results are indicated with blue symbols in Fig. 8b. The median ratio of OMI and ground overpass data (solid blue symbols in Fig. 8b) and the median ratios between model and ground data (open blue symbols) agree to within $\pm 3 \%$, but are both biased high by $2-6 \%$, depending on month. If measurements from ground and space as well as the

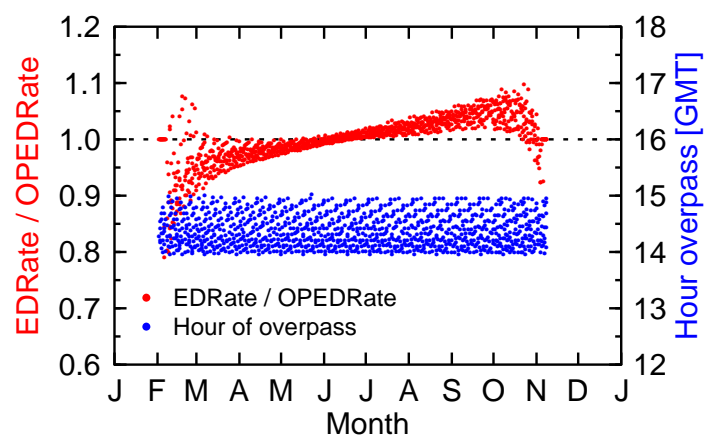

Figure 9. Ratio of EDRate / OPEDRate from the OMI data file (red, left axis) and the hour of the OMI overpass (blue, right axis) derived from the Summit data set. Data were filtered for VZA $<20^{\circ}$. The ticks on the $x$ axis indicate the start of a given month.

model results were without error, the bias would be 0 . The small bias that was actually observed is likely caused by a combination of several factors. First, attenuation by aerosols is not considered by either OMI or the model. Adjustment for this effect would reduce the bias by about $2-3 \%$ in spring (when Arctic haze is potentially present) and $1 \%$ in fall. Second, the OMI albedo climatology for Summit is 0.9 in February and October, and 0.95 at the summer solstice. The albedo used by the model is 0.97 year round. Model results should therefore exceed OMI data by about $2 \%$ most of the year. Third, ground-based data are traceable to the scale of spectral irradiance established in 1990 by the US National Institute of Standards and Technology (NIST). The current (and presumably more accurate) NIST scale of 2000 is about $1.3 \%$ higher in the UV-B than the 1990 scale (Yoon et al., 2002). If ground-based measurements were recalibrated to the NIST 2000 scale, the bias would be further reduced by about $1 \%$. Forth, the bias is within the expanded uncertainty of $6 \%$ of the ground-based measurements (Bernhard et al., 2008) and some discrepancies can therefore be expected.

As noted earlier and illustrated in Fig. 8a, the bias for the erythemal daily dose rate (DPs 2) and that of the daily dose (DP 4), increase from about $-1 \%$ in March to $14 \%$ in September. Several hypotheses were investigated and ultimately rejected to explain this increase. For example, the TOC is larger in spring than fall. If the OMI algorithm used to convert the measurements at the time of the overpass to the time of local solar noon does not take the TOC correctly into account, this could conceivably result in a bias. When the ratio of EDRate / OPEDRate (see Table 1 for acronyms) was plotted versus TOC, a strong correlation was indeed observed. However, when data were filtered by month, the correlation disappeared. For example, the ratio of EDRate/OPEDRate was similar for spring of 2010, when TOC was abnormally low, and spring of 2011, when it was abnormally high (B13). We therefore conclude that TOC cannot be the cause of the effect. Instead, the correlation with TOC only exists because TOC is effectively a proxy for time. 
EDRate is calculated from OPEDRate by the OMI UV algorithm, taking into account the difference in SZA between the time of the overpass and the time of solar noon. Figure 9 shows the annual variation of EDRate/OPEDRate for Summit. (Additional analysis not shown here indicates a similar annual cycle of EDRate/OPEDRate for all sites.) The ratio increases with month, similar to $\widetilde{\rho}_{2}$ shown in Fig. 8a, but this change could be appropriate if the viewing geometry of OMI is different in spring and fall. This is likely not the case, however. Figure 9 also indicates the time of the satellite overpass, illustrating that there is no difference between spring and fall. Additional analyses also indicate that SZAs at the time of the overpass are not systematically different in spring and fall, and that the variation in the timing of local solar noon of about $\pm 15 \mathrm{~min}$ over the course of a year is too small to explain the effect. We conclude that the time-dependent bias in DP (2) shown in Fig. 8a is caused by a problem in the conversion from OPEDRate to EDRate applied by the OMI UV algorithm. Additional analysis suggests that the pattern is likely due to a systematic error of up to $\pm 0.5^{\circ}$ in the calculation of the local-noon SZA by the algorithm. For a SZA of $80^{\circ}$ (local noon SZA on 1 March and 11 October at Summit), a $0.5^{\circ}$ error in SZA results in a UVI error of about $8 \%$.

EDDose is calculated from EDRate by the OMI UV algorithm by applying a SZA-dependent function. The function was validated by calculating a corresponding ratio from the ground-based data. The result agreed with the function applied by OMI to within $2 \%$, except at SZAs exceeding $75^{\circ}$. At these large SZAs, the conversion function also becomes dependent on TOC, which is not taken into account by the OMI UV algorithm. This is the reason why $\widetilde{\rho}_{2}$ and $\widetilde{\rho}_{4}$ show a relatively large difference of $8 \%$ for February in Fig. 8a, while the difference is smaller than $2 \%$ for the other months.

\subsubsection{Barrow, Alaska}

Barrow is close to the northernmost point of Alaska. The adjacent Chukchi Sea is typically covered by ice between November and July. Barrow is the only site considered here where the "effective surface albedo" (denoted $a_{\text {eff }}$ ) is routinely derived from ground-based measurements. $a_{\text {eff }}$ is defined as the albedo of a uniform Lambertian surface, that, when used as input into a 1-D model, reproduces the measured spectrum (Lenoble et al., 2004). $a_{\text {eff for Barrow is part }}$ of the V2 data set and calculated from the spectral effect of surface albedo on the downwelling irradiance (Bernhard et al., 2006, 2007). The uncertainty (coverage factor $k=1$ ) is 0.11 for $a_{\mathrm{eff}}=0.6$, and 0.09 for $a_{\mathrm{eff}}=0.85$. Figure $10 \mathrm{com}-$ pares $a_{\text {eff }}$ with SufAlbedo. Between March and mid-May,

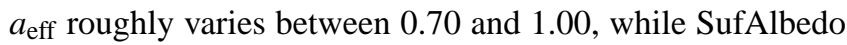
is about 0.8 . There is generally little bias between the two data sets. Snowmelt between mid-May and July leads to a sharp decrease of $a_{\text {eff }}$. While the general trend corresponds well to that of SufAlbedo, there is a large variability, with $a_{\text {eff }}$ sometimes being 0.4 smaller or larger than SufAlbedo. Su-

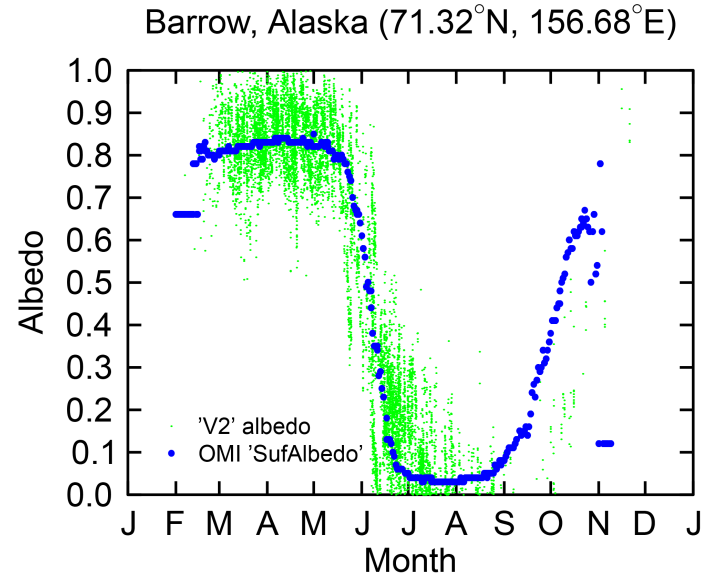

Figure 10. Comparison of effective surface albedo $a_{\text {eff }}$ derived from ground-based measurements ("V2" albedo, green marker) with SufAlbedo (blue marker) of the OMI climatology for Dis $<12 \mathrm{~km}$. $a_{\text {eff }}$ data were measured between 1991 and 2013. $a_{\text {eff }}$ data between September and November are sparse because of few clear-sky days during this period. The ticks on the $x$ axis indicate the start of a given month.

fAlbedo starts to increase again at the beginning of September, while $a_{\text {eff }}$ does not increase before October. Reliable snow coverage at Barrow was typically observed only after mid-October during the last decade (Bernhard, 2011). SufAlbedo in September and October is therefore likely too large by up to 0.3 .

The bias of OMI daily dose data at Barrow is smaller than $9 \%$ between February and April. The low value is consistent with the good agreement of $a_{\text {eff }}$ and SufAlbedo in that period. While the bias for June is also small $(-2 \%)$, the scatter for this month is large (the interquartile range is 0.84 to $1.10)$, reflecting the larger inter-annual variability in $a_{\mathrm{eff}}$ for this month (e.g., Fig. 4). The bias for September and October is 38 and $62 \%$, respectively. This large positive bias can likely be explained by the Case 1 mechanism and is further investigated in the following.

Figure 11 compares the ratio EDRate / CSEDRate (which is equivalent to the CMF) with SufAlbedo and CldOpt for the year 2007. All data are from the OMI data file. Between midFebruary and the end of April, CldOpt is 0 with few exceptions, and the corresponding CMFs are 1 , as expected. Between June and September, CldOpt is frequently larger than 5, resulting in CMFs smaller than 0.7. In October, CldOpt is 0 with few exceptions even though clouds remain frequent during this month. The low values of CldOpt are a consequence of the unrealistically large albedo for this month (Case 1), as discussed below.

Figure 12 shows statistics of cloud optical depth at Barrow from OMI (CldOpt) and ground-based observations. The box-whisker plot is based on data of all years, filtered for $\mathrm{SZA}<84^{\circ}$ and Dis $<12 \mathrm{~km}$. Ground-based COD data are 


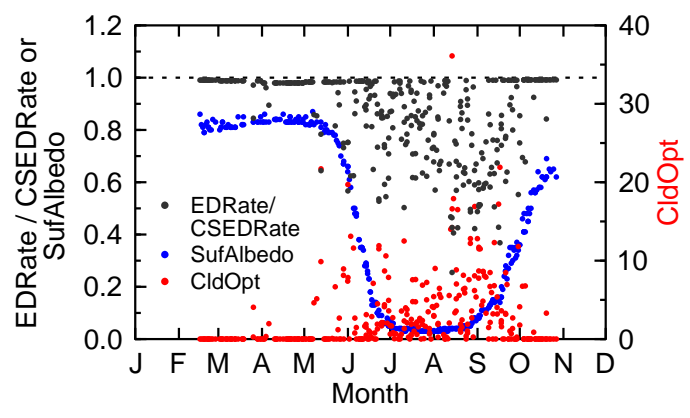

Figure 11. Comparison of ratio EDRate / CSEDRate (grey, left axis), SufAlbedo (blue, left axis) and CldOpt (red, right axis). All data are from the OMI data file for Barrow and the year 2007. The ratio EDRate / CSEDRate is equivalent to the cloud modification factor $(\mathrm{CMF})$ at $360 \mathrm{~nm}$.

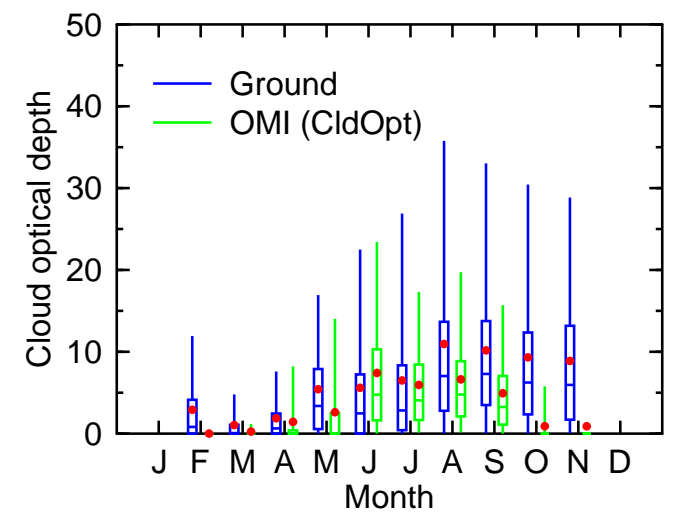

Figure 12. Box-whisker plot of cloud optical depth retrieved from ground-based measurements (blue, left of month marker) and the corresponding CldOpt data set from OMI (green, right of month marker) at Barrow. The averages for both data sets are indicated by red dots.

from the V2 data set and were derived by comparing measurements of spectral irradiance at $450 \mathrm{~nm}$ with clear-sky model results (Supplement to Bernhard et al., 2004). To a good approximation (e.g., Fig. 5.16 of Liou, 2002), COD is independent of wavelength between $450 \mathrm{~nm}$ and $360 \mathrm{~nm}$, the latter being the wavelength used by OMI to retrieve CldOpt.

COD of both data sets is close to 0 for February, March, and April. There is also very good agreement between the two data sets for July, when the surface is snow free and SufAlbedo is 0.03. Statistics of COD data from the V2 data set for August through November are similar. In contrast, CldOpt is 0 with few exceptions for October and November, confirming that the low CldOpt indicated in Fig. 11 for the year 2007 is the norm for these months. We conclude that the high bias of $62 \%$ of OMI EDDose data for October is a consequence of the high value of the albedo climatology for this month, which in turn leads to an underestimate of the COD.

\subsubsection{Andøya, Norway}

Andøya is located on the Norwegian coast north of the Arctic Circle. The bias in March and April is less than $\pm 6 \%$; SufAlbedo is about 0.25 . Winters are fairly mild due to the influence of the Gulf Stream and the relative low value of SufAlbedo is therefore reasonable. The bias for June through October is between 15 and $36 \%$, when SufAlbedo has an appropriate value of about 0.05 . The relatively large bias can therefore not be explained by the OMI albedo climatology. When data are filtered for CldOpt $=0$, the bias is reduced to 6-15\%. Hence, some portion of the bias is due to the cloud correction.

\subsubsection{Sodankylä, Finland}

The bias at Sodankylä between February and October ranges between 5 and $13 \%$ and tends to be larger in winter/spring than summer. SufAlbedo is 0.5 between February and April, drops to 0.03 by the beginning of June, and remains below 0.03 for the remainder of the summer. Sodankylä is surrounded by boreal pine forests and peatlands for which an albedo of 0.03 in the erythemal band is appropriate (Blumthaler and Ambach, 1988; Feister and Grewe, 1995). Between June and August, a bias of 4-9\% is apparent in DP (1), (2) and (4), both for all data and data filtered for $\mathrm{CldOpt}=0$. The bias is therefore systematic and not related to potential errors in the CMF applied by the OMI UV algorithm. About half of the bias is within the uncertainty of the ground measurements.

\subsubsection{Trondheim, Norway}

Trondheim is located close to the coast of central Norway and has a predominantly hemiboreal oceanic climate. The bias is between 55 and $69 \%$ between February and April. SufAlbedo for this period is 0.6. The albedo is likely too large considering that Trondheim is a city of 170000 people and located on a fjord, about $50 \mathrm{~km}$ inland from the coast of central Norway. An albedo of 0.6 enhances the clear-sky surface UV dose only by $30 \%$ (Fig. 2). A large part of the observed bias must therefore be caused by the Case 1 mechanism discussed earlier.

To provide further evidence that the Case 1 mechanism is indeed responsible for the large bias observed for Trondheim, we filtered the ground-based measurements for clearsky conditions and re-calculated the bias between OMI overpass data (DP 1) and ground-based measurements. The clearsky filter exploits the temporal variation in the measurements and takes advantage of the fact that the multi-channel radiometer used at Trondheim provides a measurement every minute. Data were considered clear-sky when the following two conditions were met: (1) The UVI at a given time must deviate by less than $1 \%$ from measurements performed 1 and 2 min before and after this time. (2) Condition (1) must be 


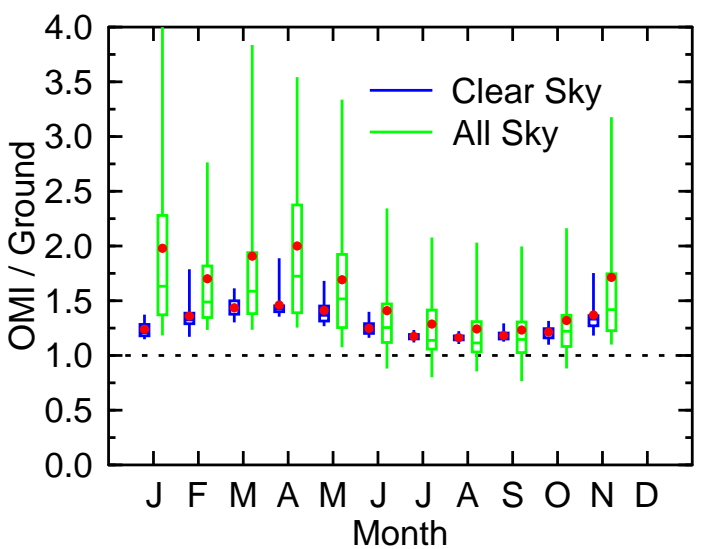

Figure 13. Ratio of overpass erythemal dose rate (DP 1) measured by OMI and the radiometer at Trondheim. Box-whiskers represent the distribution of ratios filtered for clear-sky (blue, left of month marker) and all-sky (green, right of month marker), and indicate the 5th and 95th percentile (whisker), the interquartile range (box), median (line), and average (red dot). Match-up data were filtered for $\mathrm{SZA}<84^{\circ}$ and Dis $<12 \mathrm{~km}$.

met for consecutive $15 \mathrm{~min}$ before and after the time of interest. Periods of constant cloudiness may meet condition (1), but are removed by condition (2).

The OMI data set does not include overpass data without the CMF applied. We therefore calculated the CMF from the EDRate and CSEDRate data products and divided the overpass erythemal dose rate (OPEDRate) by the CMF to reconstruct the clear-sky overpass erythemal dose rate (CSOPEDRate).

Figure 13 compares box-whiskers calculated from the ratio of CSOPEDRate and the filtered clear-sky ground data (blue) with box-whiskers calculated from OPEDRate and "all-sky" ground data. The bias and variability of the clearsky subset are much smaller than the corresponding values for all-sky data. For clear-sky data, the bias ranges between $16 \%$ in August (when SufAlbedo has an appropriate value of 0.04 ) and $44 \%$ in March and April, when SufAlbedo is 0.62. According to Fig. 2, an albedo of 0.62 enhances the clear-sky UVI by $30 \%$. This theoretical value is consistent with the albedo effect derived from the measurements (44$16 \%=28 \%$ ), assuming that the observed summer-time bias of $16 \%$ - which results from unknown causes - also applies to winter months. This analysis suggests that the actual UV albedo at Trondheim during winter is similar to that in summer, which is not surprising considering the location of the instrument close to the center of a large city.

During summer months, the biases of the clear- and allsky data sets agree to within 5\%, while in March and April, the all-sky bias exceeds the clear-sky bias by 15 and $28 \%$, respectively. Furthermore, the distributions of $\rho_{1}$ for the all-sky data set are much more skewed towards larger values compared to those of the clear-sky data set because attenuation by clouds is underestimated by OMI as a result of the large value of SufAlbedo used by the OMI UV algorithm. For example, the OMI data files indicate clear-sky conditions (i.e., $\mathrm{CldOpt}=0$ ) in $65 \%$ of data records for March and April. This percentage is far too large considering that the median cloud cover for these months is about $87 \%$ according to weather data from the Trondheim airport (https://weatherspark.com/averages/ 28896/Stj-rdal-Nord-Trondelag-Norway).

This analysis confirms that the Case 1 mechanism that leads to the overestimate by OMI is indeed composed of two components, one affecting the computation of clear-sky data and one influencing the calculation of cloud modification factors.

\subsubsection{Finse, Norway}

The instrument at Finse is located on a mountain top, $1210 \mathrm{~m}$ above sea level and about $250 \mathrm{~m}$ above the tree line. The site is typically snow-covered between the months of September and June/July. Because of this location, surface conditions within the OMI pixel are generally different from those at the instrument site, and a large difference between satellite and ground observations can be expected. This is particular true for winter months when the immediate vicinity of the instrument is snow covered while the boreal forests within the OMI pixels are not. Indeed, the bias for February through May varies between -45 and $-61 \%$. SufAlbedo has a bimodal distribution (either 0.55 or 0.70 ), which is likely too low on many occasions. Between July and September, when the ground is snow free, the bias is less than $\pm 3 \%$. This bias is smaller than for the other Norwegian sites. One contributing factor for this relatively small bias is potentially the proximity of Finse to Hardangerjøkulen, a $78 \mathrm{~km}^{2}$ large glacier located $5 \mathrm{~km}$ north of Finse. Because of the closeness to the glacier, the actual effective albedo for Finse during August could be larger than the surface albedo of 0.06 used by OMI, which would increase the ground measurement relative to the OMI observation and reduce the bias.

\subsubsection{Jokioinen, Finland}

Jokioinen is in the southwest of Finland, on the southern edge of the boreal forest belt, and has a temperate climate. Snow cover extends from December to March. The bias is $-20 \%$ between January and March, when SufAlbedo is 0.30 . The actual albedo measured under overcast skies in February 2012 was $0.70 \pm 0.08( \pm 1 \sigma)$ according to Meinander et al. (2012). The negative bias is therefore likely caused by the Case 2 mechanism. Between April and November, the bias ranges between -1 and $+6 \%$ when SufAlbedo is 0.02 . Hence, the albedo climatology used by OMI between April and December is almost ideal for this site and CMFs are calculated correctly. 
Table 3. Comparison of results from the present paper (PP) and those published by T07.

\begin{tabular}{lllrrr}
\hline Site & Month & Surface $^{\mathrm{a}}$ & \multicolumn{2}{c}{$\tilde{\rho}_{4}$} & Difference \\
\cline { 3 - 4 } & & & PP & T07 $^{\mathrm{b}}$ & $(\%)$ \\
\hline \multirow{2}{*}{ Eureka } & April & SC & 1.11 & 1.18 & 6 \\
& July & SF & 1.12 & 1.03 & -8 \\
Summit & March & PSC & 0.99 & 1.06 & 7 \\
& July & PSC & 1.11 & 1.06 & -5 \\
Barrow & March & SC & 0.99 & 1.20 & 21 \\
& July & SF & 1.1 & 1.18 & 7 \\
Sodankylä & March & SC & 1.11 & 1.10 & -1 \\
\multirow{5}{*}{ Jokioinen } & August & SF & 1.06 & 1.06 & 0 \\
& February & SC & 0.79 & 0.82 & 4 \\
& July & SF & 0.99 & 1.11 & 12 \\
\hline
\end{tabular}

a $\mathrm{SC}=$ snow cover, $\mathrm{SF}=$ snow-free, $\mathrm{PSC}=$ permanent snow cover. ${ }^{\mathrm{b}}$ Data are from Table 2 of $\mathrm{T} 07$.

\subsubsection{2 Østerås and Blindern, Norway}

Østerås and Blindern are suburbs of Oslo, about $6 \mathrm{~km}$ apart. Biases for both sites agree to within $\pm 2 \%$ for all months except February and March when the bias at Østerås is $6 \%$ smaller than at Blindern. Averaged over the year, the daily erythemal dose measured by OMI exceeds that measured at Østerås and Blindern by 7 and $8 \%$, respectively. SufAlbedo is about 0.15 between January and March and 0.02 between June and November, which are appropriate values. The influence of clouds at both sites is substantial and the observed biases suggest that the CMFs applied by the OMI UV algorithm are slightly too large.

\subsection{Comparison with results by T07}

Measurements at several sites discussed above (i.e., Eureka, Summit, Barrow, Sodankylä, and Jokioinen) have also been compared with OMI data by T07. Table 3 compares the medians $\widetilde{\rho}_{4}$ of these sites with those reported by T07. Results agree to within $\pm 8 \%$ with two exceptions: Barrow in March and Jokioinen in July. Differences of a few percent can be expected considering that the work by $\mathrm{T} 07$ is based on measurements performed between September 2004 and March 2006 only, while the present study uses data recorded between September 2004 and December 2012. In addition, values in Table 3 from the present study refer to months where the surface conditions are most certain (i.e., either snow covered or snow free), while the classification of the surface condition applied by T07 is entirely based on the OMI albedo climatology: when albedo was higher than 0.1 , snow cover was assumed, while the rest of the data were classified as snow free. As discussed above (and also emphasized by T07), the true snow conditions may diverge from the OMI albedo climatology. For Barrow, $\widetilde{\rho}_{4}$ for March (when snow is present) is 0.99 , while T07 reports a value of 1.20 . The difference may be explained by the fact that the "snow cover" value by T07 also includes data from May, September and October, months where also the present study indicates large positive biases. For July at Jokioinen, $\widetilde{\rho}_{4}$ is 0.99 according to the present study; the corresponding value by T07 is 1.11 . SufAlbedo for this month is 0.03 , which should be an accurate value, supporting the smaller bias reported here.

\subsection{Suitability of measurements at Summit to detect drifts in satellite UV data}

Results presented in Sect. 5.1.5 showed that measurements at a high elevation site located at the center of a major ice sheet, such as Summit, are potentially very helpful for satellite validation. Because of the high, homogenous surface albedo at this site, cloud effects are suppressed, resulting in very small day-to-day variations when comparing data from space and the ground. The low variability afforded the detection of systematic problems in the satellite data set and is also helpful for detecting potential long-term drifts in satellite UV observations. Compared to lower-elevation sites, Summit is less affected by increases in air temperature and their effect on albedo. For example, He et al. (2013) found that changes in short-wave surface albedo observed in Greenland between 2000 and 2012 were most pronounced at elevations between 500 and $2500 \mathrm{~m}$, ranging between -0.025 and -0.055 per decade. In contrast, the decadal change at elevations above $3000 \mathrm{~m}$ was only -0.013 . Future reductions in albedo due increased deposition of organic aerosols cannot be excluded, however. For example, the expected increase in boreal forests fire activity (Kelly et al., 2013) could have a significant impact on black carbon (BC) deposition. The BC content in the Summit snowpack is currently very low with the highest value given in the literature being $1.5-2 \mathrm{ng} \mathrm{g}^{-1}$ (Hagler et al., 2007; Doherty et al., 2010). During May and June 2011, the mean $\mathrm{BC}$ content measured over the first $1-3 \mathrm{~cm}$ of the snowpack was $0.3 \pm 0.3 \mathrm{ng} \mathrm{g}^{-1}$ and simulations suggest that its impact on albedo is negligible (Carmagnola et al., 2013). By taking into account the relationship between $\mathrm{BC}$ and snow albedo (Hadley and Kirchstetter, 2012), we conclude that even a 10-fold increase in BC at Summit would not significantly affect our ability to detect drifts in satellite UV data using ground-based measurements at this site.

\section{Conclusions and outlook}

UV data of the OMI instrument aboard NASA's Aura satellite were compared with measurements at 13 ground stations. OMI data files include several data products including the erythemal irradiance at the time of the satellite overpass, the erythemal irradiance at local solar noon, and the daily erythemal dose. The biases between OMI and ground-based instruments calculated for these data products are generally consistent, with few exceptions. For example at Summit, the bias between OMI and ground-based data evaluated at the time of 
the satellite overpass is almost constant throughout the year. In contrast, the biases for noon-time erythemal irradiance and the daily dose at this site increase from about $-1 \%$ in March to $14 \%$ in November. This annual cycle was attributed to a problem in the OMI UV algorithm, specifically the calculation of the local-noon SZA. The problem affects other sites to a similar degree.

At times when the surface albedo is known and correctly specified by the OMI albedo climatology, OMI data tend to exceed ground-based measurements by 0-11\%. Examples include Alert in April (OMI daily dose is biased high by $2 \%$ ), Ny-Ålesund in August (6\% bias), Barrow in July (10\% bias), and Østerås and Blindern year round ( $7 \%$ bias). These positive biases are quantitatively consistent with systematic differences between OMI and ground-based measurements that have been observed at unpolluted, snow-free mid- and low-latitude locations (e.g., Antón et al., 2010; Bais et al., 2015; Cordero et al., 2014; Buntoung and Webb, 2010; Mateos et al., 2013). Several studies have shown that the bias in OMI UV data increases with increasing aerosol optical depth, in particular for absorbing aerosols (Arola et al., 2009; Cachorro et al., 2010; Ialongo et al., 2008), and can reach over $40 \%$ in highly polluted areas (Cabrera et al., 2012) and in regions affected by desert dust intrusions (e.g., Anton et al., 2012). We did not address the effect of aerosols because our study focuses on pristine high latitude sites with generally low aerosol optical depth.

When the OMI albedo climatology exceeds the actual albedo, OMI data can be biased high by as much as $55 \%$ (e.g., Trondheim in February and March). The bias is caused by two effects that go in the same direction: an unrealistically high value of the OMI albedo climatology leads to a high estimate of the clear-sky irradiance and to an underestimate of attenuation by clouds. In turn, when the OMI albedo climatology is too low, OMI data can be biased low by as much as 59 \% (e.g., Ny-Ålesund in March).

Calculated biases are generally consistent with those published by T07 for those sites considered both by T07 and the present study. While relative differences can be large, absolute differences in terms of the UVI remain modest at all sites (e.g., the median bias is smaller than 2 UVI units at all sites; Fig. 7) because the large SZAs prevailing at high latitudes limit the UVI to less than 8 at all sites considered here. The relatively small UVIs observed in the Arctic and the resulting modest differences between OMI and ground observations should not lead to the conclusions that UV radiation and its accurate measurement are not important. First, the day length in the Arctic can be as long as $24 \mathrm{~h}$ and organisms that cannot escape the Sun may be exposed to similar daily UV doses than those living at lower latitudes (Bernhard et al., 2010). Second, UV reflections from snow-covered surfaces can lead to considerable UV exposure to a person's face (Cockell et al., 2001), the eyes of an animal, and man-made materials used outdoors (Heikkilä, 2014).
A better albedo climatology could greatly improve the accuracy of OMI UV data products even if year-to-year differences in albedo are not accounted for. One way of improving the albedo climatology is to exploit an apparent inconsistency in OMI data: when the albedo climatology is too large, measurement of reflectance from space during clear skies can be lower than the reflectance that is expected from the (high) value of the albedo climatology. For locations and times where such an inconsistency is repeatably observed year after year, the climatological value could be reduced until the inconsistency disappears. The alternative is to combine measurements from OMI with data from satellites that are also sensitive in the IR or microwave region and which are able to distinguish reflectance from clouds and snow.

Due to rapidly changing albedo conditions, typically taking place during spring and fall at high latitudes and in mountainous regions, surface UV radiation products will always suffer from poorly known albedo unless real-time data are available. Several satellite-based snow products have been developed recently for various applications. For example, the recently published global broadband albedo time series based on 5-day interval AVHRR data (Riihelä et al., 2013) could potentially improve the OMI albedo climatology. Such new albedo data sets should be considered when the next reprocessing of OMI surface UV data will take place.

In order to improve the daily surface UV products targeted for the general public, an alternative solution would be to use daily snow information. For example, Aqua/MODIS snow products, which are observed close in time with OMI measurements, could be implemented.

Results presented in this study also showed that measurements at a high elevation site located at the center of a major ice sheet, such as Summit, are very helpful for satellite validation. Because of the high homogenous surface albedo at this site, cloud effects are suppressed, resulting in very small day-to-day variations when comparing data from space and the ground. Measurements at such a site are therefore ideally suited to detect systematic problems or drifts over time in the satellite data set. 


\section{Appendix A: Standardized results plots}

For each site and data product, a PDF page in a standardized format is available as supplement to this paper. Figure A1 provides an annotated example of such a page. The page consists of five panels, labeled a-f. Panel (a) provides comparison statistics by months, specifically: $N_{i}, \operatorname{Min}_{i}, p_{5, i}$, $p_{25, i}, \tilde{\rho}_{i}, \bar{\rho}_{i}, p_{75, i}, p_{95, i}, \operatorname{Max}_{i}, W_{10, i}, W_{20, i}$, and $W_{30, i}$. Panel (b) shows OMI and ground-based data plotted versus time. Panel (c) is a scatter plot of OMI versus ground data. Also indicated in Panel (c) are results of two linear regressions to the data, one with the intercept calculated (red line) and one with the intercept forced through the origin (green). Dashed black lines indicate $\pm 20 \%$ deviations from the ideal 1:1 relationship (solid black line). Panel (d) consists of four sub-panels showing the ratio of OMI and ground data plotted versus time, ground-based measurements, and day of the year, plus a box-whisker plot of the ratio statistics. Panel (e) provides similar plots for the difference of OMI and ground measurements. Panel (f) provides for every month a histogram of the frequency distribution of the OMI/ground ratio. Note that the first plot of the sequence is the distribution for the whole year rather than January. The number of data points $\left(N_{i}\right)$ that were used to calculate the distributions as well as $\widetilde{\rho}_{i}$ (green, labeled "Med") and $\bar{\rho}_{i}$ (red, labeled "Avg") are also indicated. 


\section{Barrow, Alaska $\left(71.32^{\circ} \mathrm{N}, 156.68^{\circ} \mathrm{E}\right)$ EDDose, SZA less than 84 , Dist less than $12 \mathrm{~km}$}

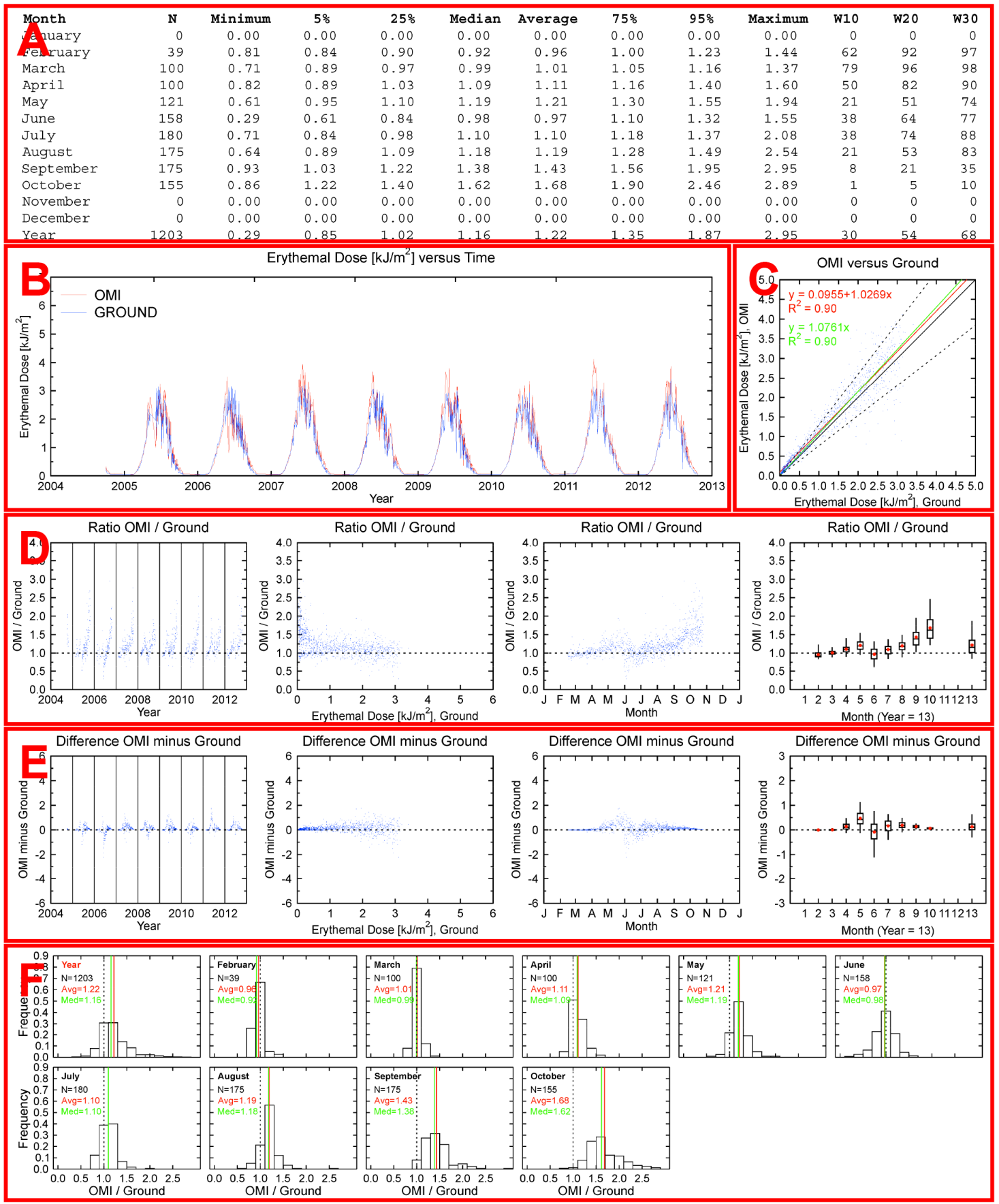

Figure A1. Example of a standardized page summarizing the results of the comparison of OMI and ground-based erythemal daily dose data at Barrow. Additional pages of this type are available as a Supplement. The contents of panels (a)-(f) are explained in the text. 


\section{The Supplement related to this article is available online at doi:10.5194/acp-15-7391-2015-supplement.}

Acknowledgements. Funding for this study was provided by the US National Science Foundation's Office of Polar Programs Arctic Sciences Section (award ARC-1203250), the Academy of Finland through the SAARA and INQUIRE projects, and the Norwegian Climate and Pollution Agency (KLIF). The work was also partly supported by the Research Council of Norway through its Centres of Excellence funding scheme, project number 223268/F50. We are grateful to the numerous dedicated individuals who have operated UV radiometers at the thirteen locations for many years. We also thank two anonymous reviewers and the editor for their constructive comments.

Edited by: S. Kazadzis

\section{References}

Antón, M., Cachorro, V. E., Vilaplana, J. M., Toledano, C., Krotkov, N. A., Arola, A., Serrano, A., and de la Morena, B.: Comparison of UV irradiances from Aura/Ozone Monitoring Instrument (OMI) with Brewer measurements at El Arenosillo (Spain) Part 1: Analysis of parameter influence, Atmos. Chem. Phys., 10, 5979-5989, doi:10.5194/acp-10-5979-2010, 2010.

Anton, M., Valenzuela, A., Román, R., Lyamani, H., Krotkov, N., Arola, A., Olmo, F. J., and Alados-Arboledas, L.: Influence of desert dust intrusions on ground-based and satellite-derived ultraviolet irradiance in southeastern Spain, J. Geophys. Res., 117, D19209, doi:10.1029/2012JD018056, 2012.

Arola, A., Kazadzis, S., Lindfors, A., Krotkov, N., Kujanpää, J., Tamminen, J., Bais, A., di Sarra, A., Villaplana, J. M., Brogniez, C., Siani, A. M., Janouch, M., Weihs, P., Webb, A., Koskela, T., Kouremeti, N., Meloni, D. Buchard, V. Auriol, F., Ialongo, I., Staneck, M., Simic, S., Smedley, A., and Kinne, S.: A new approach to correct for absorbing aerosols in OMI UV, Geophys. Res. Lett., 36, L22805, doi:10.1029/2009GL041137, 2009.

Bais, A., Blumthaler, M., Gröbner, J., Seckmeyer, G., Webb, A. R., Görts, P., Koskela, T., Rembges, D., Kazadzis, S., Schreder, J., Cotton, P., Kelly, P., Kouremeti, N., Rikkonen, K., Studemund, H., Tax, R., and Wuttke, S.: Quality assurance of spectral ultraviolet measurements in Europe through the development of a transportable unit (QASUME), in: Ultraviolet Ground- and SpaceBased Measurements, Models, and Effects II, edited by: Gao, W., Herman, J. R., Shi, G., Shibasoki, K., and Slusser, J. R., SPIE, Bellingham, WA, USA, 4896, 232-238, 2003.

Bais, A. F., McKenzie, R. L., Bernhard, G., Aucamp, P. J., Ilyas, M., Madronich, S., and Tourpali, K.: Ozone depletion and climate change: Impacts on UV radiation, Photochem. Photobiol. Sci., 14, 19-52, 2015.

Bernhard, G.: Trends of solar ultraviolet irradiance at Barrow, Alaska, and the effect of measurement uncertainties on trend detection, Atmos. Chem. Phys., 11, 13029-13045, doi:10.5194/acp-11-13029-2011, 2011.
Bernhard, G., Booth, C. R., and McPeters, R. D.: Calculation of total column ozone from global UV spectra at high latitudes, J. Geophys Res., 108, 4532, doi:10.1029/2003JD003450, 2003.

Bernhard, G., Booth, C. R., and Ehramjian, J. C.: Version 2 data of the National Science Foundation's Ultraviolet Radiation Monitoring Network: South Pole, J. Geophys. Res., 109, D21207, doi:10.1029/2004JD004937, 2004.

Bernhard, G., Booth, C. R., Ehramjian, J. C., and Nichol, S. E.: UV climatology at McMurdo Station, Antarctica, based on version 2 data of the National Science Foundation's Ultraviolet Radiation Monitoring Network, J. Geophys. Res., 111, D11201, doi:10.1029/2005JD005857, 2006.

Bernhard, G., Booth, C. R., Ehramjian, J. C., Stone, R., and Dutton, E. G.: Ultraviolet and visible radiation at Barrow, Alaska: climatology and influencing factors on the basis of version $2 \mathrm{Na}-$ tional Science Foundation network data, J. Geophys. Res., 112, D09101, doi:10.1029/2006JD007865, 2007.

Bernhard, G., Booth, C. R., and Ehramjian, J. C.: Comparison of UV irradiance measurements at Summit, Greenland; Barrow, Alaska; and South Pole, Antarctica, Atmos. Chem. Phys., 8, 4799-4810, doi:10.5194/acp-8-4799-2008, 2008.

Bernhard, G., Booth, C. R., and Ehramjian, J. C.: Climatology of ultraviolet radiation at high latitudes derived from measurements of the National Science Foundation's Ultraviolet Spectral Irradiance Monitoring Network, in: UV Radiation in Global Climate Change: Measurements, Modeling and Effects on Ecosystems, edited by: Gao, W., Schmoldt, D. L., and Slusser, J. R., Tsinghua University Press, Beijing and Springer, New York, 544 pp., 2010.

Bernhard, G., Dahlback, A., Fioletov, V., Heikkilä, A., Johnsen, B., Koskela, T., Lakkala, K., and Svendby, T.: High levels of ultraviolet radiation observed by ground-based instruments below the 2011 Arctic ozone hole, Atmos. Chem. Phys., 13, 10573-10590, doi:10.5194/acp-13-10573-2013, 2013.

Blumthaler, M. and Ambach, W.: Solar UVB-albedo of various surfaces, Photochem. Photobiol., 48, 85-88, 1988.

Buntoung, S. and Webb, A. R.: Comparison of erythemal UV irradiances from Ozone Monitoring Instrument (OMI) and groundbased data at four Thai stations, J. Geophys. Res., 115, D18215, doi:10.1029/2009JD013567, 2010.

Cabrera, S., Ipiña, A., Damiani, A., Cordero, R. R., and Piacentini, R. D.: UV index values and trends in Santiago, Chile $\left(33.5^{\circ} \mathrm{S}\right)$ based on ground and satellite data, J. Photoch. Photobio. B, 115, 73-84, 2012.

Cachorro, V. E., Toledano, C., Antón, M., Berjón, A., de Frutos, A., Vilaplana, J. M., Arola, A., and Krotkov, N. A.: Comparison of UV irradiances from Aura/Ozone Monitoring Instrument (OMI) with Brewer measurements at El Arenosillo (Spain) - Part 2: Analysis of site aerosol influence, Atmos. Chem. Phys., 10, 11867-11880, doi:10.5194/acp-10-11867-2010, 2010.

Carmagnola, C. M., Domine, F., Dumont, M., Wright, P., Strellis, B., Bergin, M., Dibb, J., Picard, G., Libois, Q., Arnaud, L., and Morin, S.: Snow spectral albedo at Summit, Greenland: measurements and numerical simulations based on physical and chemical properties of the snowpack, The Cryosphere, 7, 1139-1160, doi:10.5194/tc-7-1139-2013, 2013.

Cockell, C. S., Scherer, K., Horneck, G., Rettberg, P., Facius, R., Gugg-Helminger, A., Driscoll, C., and Lee, P.: Exposure of Arctic field scientists to ultraviolet radiation evaluated using personal dosimeters, Photochem. Photobiol., 74, 570-578, 2001. 
Commission Internationale de l'Éclairage (CIE): Erythema Reference Action Spectrum and Standard Erythema Dose, CIE S007E1998, CIE Central Bureau, Vienna, Austria, 1998.

Cordero, R. R., Seckmeyer, G., Damiani, A., Riechelmann, S., Rayas, J., Labbe, F., and Laroze, D.: The world's highest levels of surface UV, Photochem. Photobiol. Sci., 13, 70-81, 2014.

Doherty, S. J., Warren, S. G., Grenfell, T. C., Clarke, A. D., and Brandt, R. E.: Light-absorbing impurities in Arctic snow, Atmos. Chem. Phys., 10, 11647-11680, doi:10.5194/acp-1011647-2010, 2010.

Feister, U. and Grewe, R.: Spectral albedo measurements in the UV and visible region over different types of surfaces, Photochem. Photobiol., 62, 736-744, 1995.

Grenfell, T. C., Warren, S. G., and Mullen P. C.: Reflection of solar radiation by the Antarctic snow surface at ultraviolet, visible, and nearinfrared wavelengths, J. Geophys. Res., 99, 18669-18684, 1994.

Gröbner, J., Schreder, J., Kazadzis, S., Bais, A. F., Blumthaler, M., Görts, P., Tax, R., Koskela, T., Seckmeyer, G., Webb, A. R., and Rembges D.: Traveling reference spectroradiometer for routine quality assurance of spectral solar ultraviolet irradiance measurements, Appl. Opt., 44, 5321-5331, 2005.

Hadley, O. L. and Kirchstetter, T. W.: Black-carbon reduction of snow albedo, Nature Clim. Change, 2, 437-440, 2012.

Hagler, G., Bergin, M., Smith, E., and Dibb, J.: A summer time series of particulate carbon in the air and snow at Summit, Greenland, J. Geophys. Res., 112, D21309, doi:10.1029/2007JD008993, 2007.

He, T., Liang, S., Yu, Y., Wang, D., Gao, F., and Liu, Q.: Greenland surface albedo changes in July 1981-2012 from satellite observations, Environ. Res. Lett., 8, 044043, doi:10.1088/17489326/8/4/044043, 2013.

Heikkilä, A.: Methods for assessing degrading effects of UV radiation on materials, Finnish Meteorological Institute Contributions No 111, ISBN 978-951-697-843-0, Unigrafia Oy, Helsinki, Finland, 2014.

Ialongo, I., Casale, G. R., and Siani, A. M.: Comparison of total ozone and erythemal UV data from OMI with ground-based measurements at Rome station, Atmos. Chem. Phys., 8, 3283-3289, doi:10.5194/acp-8-3283-2008, 2008.

International Organization for Standardization/Commission Internationale de l'Eclairage (ISO/CIE): Erythema Reference Action Spectrum and Standard Erythema Dose, ISO 17166/CIE S007/E1998, ISO, Geneva, Switzerland, 1999.

Kelly, R., Chipman, M. L., Higuera, P. E., Stefanova, I., Brubaker, L. B., and Hu, F. S.: Recent burning of boreal forests exceeds fire regime limits of the past 10,000 years, P. Natl. Acad. Sci., 110, 13055-13060, 2013.

Lenoble, J.: Modeling of the influence of snow reflectance on ultraviolet irradiance for cloudless sky, Appl. Opt., 37, 2441-2447, 1998.

Lenoble, J., Kylling, A., and Smolskaia, I.: Impact of snow cover and topography on ultraviolet irradiance at the alpine station of Briançon, J. Geophys. Res., 109, D16209, doi:10.1029/2004JD004523, 2004.

Liou, K.-N.: An introduction to atmospheric radiation, Vol. 84, Academic press, San Diego, California, 2002.
Mateos, D., Bilbao, J., Kudish, A. I., Parisi, A. V., Carbajal, G., di Sarra, A., Román, R., and de Miguel, A.: Validation of OMI satellite erythemal daily dose retrievals using ground-based measurements from fourteen stations, Remote Sens. Environ., 128, 1-10, doi:10.1016/j.rse.2012.09.015, 2013.

Mayer, B. and Kylling, A.: Technical note: The libRadtran software package for radiative transfer calculations - description and examples of use, Atmos. Chem. Phys., 5, 1855-1877, doi:10.5194/acp-5-1855-2005, 2005.

McKinlay, A. F. and Diffey, B. L.: A reference action spectrum for ultraviolet induced erythema in human skin, in: Commission International de l'Éclairage (CIE), Research Note, 6, No. 1, 17-22, 1987.

Meinander, O., Heikkilä, A., Riihelä, A., Aarva, A., Kontu, A., Kyrö, E., Lihavainen, H., Kivekäs, N., Virkkula, A., Järvinen, O., Svensson, J., and De Leeuw, G.: About seasonal Arctic snow UV albedo at Sodankylä and UV-VIS albedo changes induced by deposition of soot, Proceedings of Finnish Center of Excellence in 'Physics, Chemistry, Biology and Meteorology of Atmospheric Composition and Climate Change', and Nordic Center of Excellence in 'Cryosphere-Atmosphere Interactions in a Changing Arctic Climate, Annual Meetings 2012, Report Series in Aerosol Science, 134, 470-473, 2012.

Mims III, F. M. and Frederick, J. E.: Cumulus clouds and UVB, Nature, 371, p. 291, doi:10.1038/371291a0, 1994.

Nichol, S. E, Pfister, G., Bodeker, G. E., McKenzie, R. L., Wood, S. W., and Bernhard, G.: Moderation of cloud reduction of UV in the Antarctic due to high surface albedo, J. Appl. Meteorol., 42, 1174-1183, 2003.

Riihelä, A., Manninen, T., Laine, V., Andersson, K., and Kaspar, F.: CLARA-SAL: a global 28 yr timeseries of Earth's black-sky surface albedo, Atmos. Chem. Phys., 13, 3743-3762, doi:10.5194/acp-13-3743-2013, 2013.

Tanskanen, A.: Lambertian surface albedo climatology at $360 \mathrm{~nm}$ from TOMS data using moving time-window technique, in: Ozone, Proceedings of the XX Quadrennial Ozone Symposium, 1-8 June 2004, Kos, Greece, edited by: Zerefos, C. S., Volume II, 1159-1160, published by University of Athens, Athens, Greece, 2004.

Tanskanen, A., Lindfors, A., Määttä, A., Krotkov, N., Herman, J., Kaurola, J., Koskela, T., Lakkala, K., Fioletov, V., Bernhard, G., McKenzie, R., Kondo, Y., O’Neill, M., Slaper, H., den Outer, P., Bais, A. F., and Tamminen, J.: Validation of daily erythemal doses from Ozone Monitoring Instrument with groundbased UV measurement data, J. Geophys. Res., 112, D24S44, doi:10.1029/2007JD008830, 2007.

VanCuren, R. A., Cahill, T., Burkhart, J., Barnes, D, Zhao, Y., Perry, K., Cliff, S., and McConnell, J.: Aerosols and their sources at Summit Greenland-first results of continuous size-and timeresolved sampling, Atmos. Environ., 52, 82-97, 2012.

Webb, A. R., Slaper, H., Koepke, P., and Schmalwieser, A. W.: Know your standard: clarifying the CIE erythema action spectrum, Photochem. Photobiol., 87, 483-486, 2011. 
World Health Organization (WHO): Global Solar UV Index: a Practical Guide, 28 pp., published by World Health Organization (WHO), World Meteorological Organization (WMO), United Nations Environment Programme (UNEP) and the International Commission on Non-Ionizing Radiation Protection (ICNIRP), WHO, Geneva, Switzerland, available at: http://www.who.int/ uv/publications/en/GlobalUVI.pdf (last access: 20 March 2015), 2002.
Yoon, H. W., Gibson, C. E., and Barnes P. Y.: Realization of the National Institute of Standards and Technology detector-based spectral irradiance scale, Appl. Opt., 41, 5879-5890, 2002. 